\title{
Evolutionary changes in the orbits and palatal openings of early tetrapods, with emphasis on temnospondyls
}

\begin{tabular}{|r|l|}
\hline Journal: & $\begin{array}{l}\text { Earth and Environmental Science Transactions of the Royal Society of } \\
\text { Edinburgh }\end{array}$ \\
\hline Manuscript ID & Draft \\
\hline Manuscript Type: & Early Vertebrate Evolution \\
\hline Date Submitted by the Author: & n/a \\
\hline Complete List of Authors: & $\begin{array}{l}\text { Witzmann, Florian; Museum fur Naturkunde - Leibniz-Institut fur } \\
\text { Evolutions- und Biodiversitatsforschung, Evolutionäre Morphologie } \\
\text { Ruta, Marcello; University of Lincoln, School of Life Sciences }\end{array}$ \\
\hline Keywords: & $\begin{array}{l}\text { interpterygoid vacuities, orbit openings, skull spatial relationships, shape, } \\
\text { size }\end{array}$ \\
\hline
\end{tabular}




\title{
Evolutionary changes in the orbits and palatal openings of early tetrapods, with emphasis on temnospondyls
}

\section{Florian Witzmann ${ }^{1, *}$ and Marcello Ruta ${ }^{2}$}

\author{
${ }^{1}$ Museum für Naturkunde, Leibniz Institute for Evolution and Biodiversity Science, \\ 10115 Berlin, Germany \\ ${ }^{2}$ School of Life Sciences, University of Lincoln, Lincoln LN6 7DL, UK \\ * Corresponding author, e-mail: Florian.Witzmann@mfn.berlin
}

RUNNING TITLE: Evolution of orbits and palatal openings in early tetrapods 
ABSTRACT: Open palates with large interpterygoid vacuities are a diagnostic trait of temnospondyl amphibians, but their functional roles or potential in phylogenetic reconstruction have long remained elusive. The present work examines patterns of shape and size variation in the orbits and interpterygoid vacuities of temnospondyls, based on an informal supertree consisting of 69 temnospondyl taxa and "outgroups" of 13 additional early tetrapod taxa (colosteids, an embolomere, "microsaurs", and nectrideans). The statistical methods encompass - among others - Standard Eigenshape analysis (ES) to quantify differences among the orbit and vacuity outlines, description of orbit and vacuity dimensions relative to skull size through linear measurements from which several ratios were derived, and a phylogenetically corrected Principal Component Analysis of the logit-transformed ratios to characterize proportional changes in orbits and vacuities. We examined rates of evolutionary change and their associated shifts using motmot, and in order to assess the strength and significance of the correlations between shape and size for both orbits and vacuities, we conducted a series of Phylogenetic Generalized Least Squares analyses (PGLS). Although orbits and interpterygoid vacuities appear to have a rather simple outline, both types of openings reveal complex models of shape and size change in temnospondyl evolution. These changes are mostly predicted by phylogenetic structure, and this has interesting implications for the use of orbit and vacuity characters in phylogeny reconstruction. The fact that most of the significant PGLS models show no correlation between orbit shape and enlargement of interpterygoid vacuities lends support to the hypothesis that the interpterygoid vacuities evolved first for accommodation of the anterior jaw muscles, and secondary for eye muscles.

KEY WORDS: interpterygoid vacuities, lissamphibians, orbit openings, shape, size, skull spatial relationships 
The temnospondyls are the most diverse and longest-ranging group of early tetrapods, with a fossil record extending from the Early Carboniferous to the Early Cretaceous. They are of great zoological significance as they are hypothesized to have given rise to lissamphibians via one particular superfamily, the dissorophoids (e.g., Milner 1990, 1993; Schoch 2014; for different hypothesis of lissamphibian origins, see Marjanović and Laurin 2013). One of the diagnostic features of temnospondyls is the presence of an open palate, in which enlarged and smooth-edged palatal openings (interpterygoid vacuities; hereafter, vacuities for brevity) are situated between the usually slender and triradiate pterygoids, laterally, and the elongate and strut-like cultriform process of the parasphenoid, medially (Fig. 1). Such vacuities often greatly exceed the size of the orbits (Milner 1990; Milner \& Sequeira 1994; Schoch 2013, 2014; Schoch \& Milner 2004, 2014; Witzmann \& Werneburg 2017). In several temnospondyls belonging to a wide range of clades, the vacuities were covered in life by a flexible flap of denticulated platelets embedded in the skin of the palate (Gee et al. 2017). The majority of other early tetrapods, and their fish-like ancestors, usually have comparatively broad pterygoids that approach or abut against the parasphenoid or meet along the ventral mid line of the skull. As a result, the vacuities of non-temnospondyl early tetrapods are either small and narrow (in some cases, even slit-like) or absent altogether (Fig. 2; Clack 2012). However, exceptions are known among the "lepospondyls" (now widely recognised as an informal array of separate groups in need of revision, Pardo et al. 2017), such as the most derived diplocaulid nectrideans (e.g., Diplocaulus) and certain "microsaurs" (e.g., Hyloplesion), in which the somewhat enlarged vacuities resemble in general proportions those of temnospondyls (Carroll \& Gaskill 1978; Milner 1980; Carroll et al. 1998). Among extant tetrapods, enlarged vacuities are observed in lissamphibians, particularly anurans and urodeles (Duellman \& Trueb 1994; Schoch 2014). If the temnospondyl hypothesis of lissamphibian ancestry is correct (Ruta \& Coates 2007; 
Sigurdsen \& Green 2011; Schoch 2014), then the open palate of lissamphibians is a direct heritage of their temnospondyl ancestry.

The functional significance of the vacuities has long been a matter of debate. Extant anurans and urodeles can retract their eyeballs into the buccal cavity through the action of specialized eye muscles inserted onto the borders of the vacuities. This retraction facilitates the swallowing of prey (Deban \& Wake 2000; Levine et al. 2004). Recently, Witzmann \& Werneburg (2017) identified attachment sites for the eye retractor and levator muscles in temnospondyls. The striking similarities in the structure and position of these attachment sites between temnospondyls, on the one hand, and anurans/urodeles, on the other, suggests that temnospondyls were similarly capable of retracting their eyeballs during swallowing. However, the osteological correlates of muscle and tendon insertions suggest that in most temnospondyls (with the exception of the short-snouted dissorophoids), the middle and anterior margins of the vacuities provided additional muscle attachment sites and space for the anterior portion of the jaw adductor musculature (Witzmann \& Werneburg 2017). The results of the finite element analysis of temnospondyl skulls conducted by Lautenschlager et al. (2016) indicated that this particular skull construction, consisting of enlarged vacuities and an anterior extension of the jaw muscles, lead to a better transmission of muscle forces and increase in bite forces. However, the study of Lautenschlager et al. (2016) did not indicate any significant effect of the vacuities on the distribution of stress and strain forces during feeding. These results are reminiscent of the similarly neutral effects associated with orbit size and position, such as were discussed by Marcé-Nogué et al. (2015).

A second functional interpretation of the temnospondyl vacuities is related to breathing. The broad, often spade-shaped, and flat skulls and the abbreviated and stumpy ribs (except in very large species) of temnospondyls suggest that these animals were buccal pumpers, like extant lissamphibians, rather than costal breathers, like extant amniotes (Janis \& Keller 
2001), i.e. they were presumably capable of slamming air down their throat and into their lungs via vertical movements of their buccal floor. Early anatomists, such as Francis (1934), suggested that the eye levator muscle raises the skin in the vacuities of salamanders, which results in an expansion of the mouth cavity during buccal pumping. Later, a similar breathing mechanism was suggested for temnospondyls (Clack 1992, 2012; Laurin 2010; Schoch 2014). Francis' (1934) hypothesis, however, has not been tested thus far in extant lissamphibians.

The vacuities of early tetrapods vary considerably in proportions, dimensions (relative to the skull), outline, and degrees of lengthening and widening. Similarly, the orbits - which provide a proxy for the size and location of the eyeballs and their associated muscles - differ greatly in size and location on the skull roof, as well as in their position relative to that of the vacuities. For example, both vacuities and orbits are propotionally very large in dissorophoids, particularly as a result of heterochrony-induced (e.g., progenetic dwarfism) patterning of the skull bones in several species (Milner 1993; Fröbisch \& Schoch 2009; Schoch 2014). In stereospondyls, a group of predominantly Triassic temnospondyls often attaining large sizes, the vacuities are conspicuous and much larger than the orbits, and these, in turn, may be aligned vertically either with the posterior (e.g., several capitosauroids) or the anterior margins of the vacuities (e.g., several metoposaurids).

The fossil record of early tetrapods in general, and especially temnospondyls, provides a rich source of observable and measurable data on the palate. The palate is complex and variable and is amenable to analyses of morphological change in a phylogenetic framework (Kimmel et al. 2009). Based on published descriptions and restorations of early tetrapod palates and using a supertree of representative taxa (with emphasis on temnospondyls), we carried out morphometric analyses of orbit and vacuity outlines, examined models of evolutionary change in both these structures, and investigated the correlation between their 
shapes and sizes. To what extent are enlarged and similarly shaped vacuities the result of phylogenetic relatedness or convergent functional roles? Do changes in orbit and vacuity shapes track each other across phylogeny, and can their morphologies be used to differentiate groups? Finally, how do proportional changes in those structures correlate with their relative sizes?

\section{Materials and Methods}

Phylogenetic comparative analyses (e.g., Garamszegi 2014) were undertaken in the 'R' environment for statistical computing and graphics (http://www.R-project.org/; v. 3.4.3).

\subsection{Taxon selection and phylogeny}

The phylogenetic frame of reference for our study consists of an informal supertree (e.g., Butler \& Goswami 2008), inclusive of 69 temnospondyls and 13 additional early tetrapod taxa, the latter referred to as "outgroups" (Table 1). The outgroups consist of two colosteids, one embolomere, four "microsaurs", and six nectrideans. Their inclusion serves to test the hypothesis that their vacuities are morphologically different from those of temnospondyls. We sought to provide an adequate representation of temnospondyls, but we restricted our choice to taxa with well-preserved, undistorted skull material. They include six edopoids, a Balanerpeton-Dendrerpeton-Dendrysekos group (“Dendrerpetidae”), seven dvinosaurs, 17 dissorophoids, two zatracheids, three eryopids, a paraphyletic array of "archegosauriforms" (six taxa), rhinesuchids (one taxon), and rhytidosteans (three taxa), nine trematosauroids, a "plagiosaur-brachyopid" (three plagiosaurids plus one brachyopid) group, and eight capitosauroids.

The branching topology for temnospondyls (Fig. 3) mostly follows Schoch (2013). For tests of group separation in morphospace (see below), however, we placed zatracheids and 
eryopids into a single grade assemblage. In the supertree, zatracheids form the sister group to dissorophoids, and eryopids join the "archegosauriform"-rhinesuchid-rhytidostean array; e.g., Schoch \& Milner 2014). The rationale behind the zatracheid-eryopoid grouping is that these two clades exhibit similar cranial constructions. Indeed, these similarities have sometimes been used to postulate a close relationship between them (e.g., Ruta \& Bolt 2006), although this view has been challenged (e.g., Schoch 2013). By forcing these two groups to cluster together, we sought to provide a stringent test of a "null" scenario in which the evolutionary changes in skull constructions (specifically, the proportional differences in skull openings) did not experience significant shifts at major branching events in temnospondyl history.

First stratigraphic appearance data (FAD) for all taxa were gathered from published literature supplemented by information in the Paleobiology Database (https://paleobiodb.org). The FADs were used to estimate branch lengths (i.e., their duration in millions of years). To build a time-calibrated version of the supertree, we employed the "equal" method (Ruta et al. 2006; Brusatte et al. 2008) in the 'DatePhylo' function of the strap R package (Bell \& Lloyd 2015). With this method, branches descending from a given node are allowed an equal share of the duration of the immediately preceding (ancestral) branch length (Wang \& Lloyd 2016; for additional explanations, see also: http://graemetlloyd.com/methdpf.html). A root of one million years was appended to the supertree. Although several short-duration branches may result with the "equal" method (which may have an impact on evolutionary rate estimates), such a method makes the fewest possible assumptions about divergence times. The resulting tree was plotted onto a stratigraphic scale with the 'DatePhylo' function in the strap R package (Bell \& Lloyd 2015).

\subsection{Shape characterization of orbits and vacuites}


We applied Standard Eigenshape (SE) analysis (Lohmann 1983; MacLeod 1999) to quantify differences among the orbit and vacuity outlines. This type of outline-based morphometric analysis quantifies changes in the angle delimited by segments connecting consecutive pairs of landmarks around an outline. We traced the vacuities on the ventral side of the right palatal halves of all taxa and superimposed the right orbit outlines.

The outlines were digitized in tpsDIG2 v. 2.32 (http://life.bio.sunysb.edu/morph/softdataacq.html) and subjected to SE via online tools at www.morpho-tools.net. The SE analyses used a variance-covariance matrix of angular deviations, with mean-centering and standardizing options in effect to quantify the departure of outlines from circularity and to remove all dimensional, rotational, and position effects. The shape variables (eigenscores) on the first two shape axes (eigenaxes) were used to build empirical morphospace plots and as response variables in some subsequent analyses.

\subsection{Size characterization of orbits and vacuities}

We described the dimensions of the orbits and vacuities relative to the skull size through linear measurements from which we derived several ratios (Fig. 1). We measured the ratios of each of the orbit and vacuity lengths (orbl; vacl) to skull length (sl), and of each of the orbit and vacuity widths (orbw; vacw) to skull width (sw). We also measured the ratios of orbit to vacuity lengths and orbit to vacuity widths. These two ratios summarize relative proportions between orbits and vacuities irrespective of their location on the skull and differences in skull build. The orbit and vacuity lengths are the greatest antero-posterior distances between the anterior and posterior margins of these structures and are measured parallel to the skull's longitudinal axis. The orbit and vacuity widths are the greatest transverse distances between the lateral and medial margins of these structures and are measured perpendicular to the skull's longitudinal axis. The skull length is the distance between the anterior extremity of the 
conjoined premaxillae, in dorsal or ventral aspect, and a plane passing through the posterior borders of the quadrate condyles. The skull width is the greatest distance between its lateral margins in dorsal or ventral aspect.

All six ratios were logit-transformed prior to statistical treatment. Logit transformations were carried out with the 'logit' function of the car R package (Fox \& Weisberg 2011). This transformation has many desirable properties. For example, it stabilizes the variance of a ratio distribution (this also applies to proportions and percentages) by "stretching" the extreme values of the distribution, so that small increments near each end of the distribution appear more widely spaced on the ratio scale (e.g., Sokal \& Rohlf 1995).

As an additional way to characterize proportional changes in orbits and vacuities, we carried out a phylogenetically corrected Principal Component Analysis (hereafter, phylPCA) of the logit-transformed ratios - logit(orbl/sl); logit(vacl/sl); logit(orbw/sw); logit(vacw/sw); logit(orbl/vacl); logit(orbw/vacw) - using the 'phyl.pca' function of the phytools R package (Revell 2009), with the variance-covariance matrix method (appropriate in this case, because all variables are non-dimensional) and Brownian Motion (BM; an undirected random walk model of trait change) to obtain the data correlation structure (i.e., BM was used to describe trait covariance across taxa based upon phylogenetic relatedness; Revell 2009).

\subsection{Tests of group differences}

In order to assess the statistical significance of group separation based upon shape and size variables, we applied two non-parametric tests to the eigenscores from all eigenaxes (for the ES analyses of orbit and vacuity outlines) and to the Principal Component scores from all axes (for the phylPCA analysis of the logit-transformed ratios). The two tests are a one-way non-parametric multivariate analysis of variance (PERMANOVA; $\mathrm{H}_{0}$ : the different groups are characterized by similar multivariate means; Anderson 2001) and an analysis of similarity 
(ANOSIM; $\mathrm{H}_{0}$ : the rank-converted distances between taxa that belong to a group are similar to the rank-converted distances between taxa in different groups; Clarke 1993). In all cases, we ran both tests with 9999 random data permutations to evaluate the significance of the global tests' statistics, and we reported the significance of pair-wise group comparisons both with and without Bonferroni correction for multiple comparisons (Supplementary Table 1).

\subsection{Patterns of cranial evolution}

The tempo and mode of phenotypic changes in the temnospondyl skull are being investigated by us as part of ongoing research on models of phenotypic evolution in early tetrapods. Here, we report on preliminary results that focus on cranial openings.

1.5.1. Phylogenetic signal. We employed the phylosignal R package (Keck et al. 2016) to quantify signal in the shape and size variables, using two signal statistics, namely Pagel's lambda and Blomberg's K (Pagel 1999; Blomberg et al. 2003), the significance of which was assessed through 999 randomizations of data structure (Supplementary Table 2).

1.5.2. Evolutionary models. The 'fitContinuous' function of the geiger R package (Harmon et al. 2008) was used to compare the fits of nine evolutionary models for various shape and size variables to the time-calibrated phylogeny (Supplementary Table 2), as follows: BM (Brownian Motion); delta; drift; early burst; kappa; lambda; OrnsteinUhlenbeck (OU); trend; white noise. For each model, we tabulated its Maximum Likelihood (ML), Akaike Information Criterion (AIC), and modified AIC for heterogeneous sample sizes (AICc) (Burnham \& Anderson 1998). Both AIC and AICc values were ranked according to their weights (AICw; $\mathrm{AICcw}$ ), the best-fitting model being the one with the largest $\mathrm{AICw}$ or AICcw. Such weights were calculated with the 'aicw' function in geiger.

1.5.3. Rates and shifts. We examined rates of evolutionary change and their associated shifts using the "tm1" model of trait evolution in motmot (Thomas \& Freckleton 2012). The 
model was fitted to the first 10 eigenaxes for both orbits and vacuities (summarizing, respectively, $\sim 65.8 \%$ and $\sim 79.5 \%$ of the total shape variance), as well as to cranial ratios. For cranial ratios, we experimented with different data partitions, specifically using all six ratios, the four ratios describing the size of the orbits and the vacuities relative to the skull [logit(orbl/sl); logit(vacl/sl); logit(orbw/sw); logit(vacw/sw)], and the two ratios describing the proportions of the orbits and the vacuities relative to one another [logit(orbl/vacl); logit(orbw/vacw)] (Supplementary Table 3). In all cases, we allowed a maximum of five rate shifts to be retrieved on the phylogeny given a minimum clade size of three taxa (i.e., only branches with three or more taxa were considered for shift detection).

\subsection{Correlations between shape and size}

In order to assess the strength and significance of the correlations between shape and size for both orbits and vacuities, we conducted a series of Phylogenetic Generalized Least Squares analyses (PGLS; Mundry 2014; Symonds \& Blomberg 2014), with shape (response) variables regressed against size (predictor) variables, using the 'pgls' function of the caper R package (Orme et al. 2013). Furthermore, we ran diagnostic tests to check how well the fitted PGLS model conformed to various statistical assumptions of phylogenetic regression (e.g., normal distribution of phylogenetic residuals; non-homogeneity in bivariate scatterplots of residual vs. fitted values; e.g., Mundry 2014; Symonds \& Blomberg 2014).

In total, 16 PGLS analyses were run (Supplementary Table 4). For each of the first two eigenaxes that relate to orbit and vacuity shapes (a total of four response variables), we quantified the correlation with four of the logit-transformed ratios, namely those that describe the lengths of orbits and vacuities relative to skull length (logit(orbl/sl); logit(vacl/sl)) and those that describe the widths of orbits and vacuities relative to skull width (logit(orbw/sw); logit(vacw/sw)) (a total of four predictor variables). While additional comparisons are 
possible with consideration of the other two logit-transformed ratios (logit(orbl/vacl); $\operatorname{logit}($ orbw/vacw)), we opted for those ratios that capture proportional differences in each of the two skull openings considered here in relation to the entire skull.

\section{Results}

\subsection{Shape variation}

The patterns of morphospace occupation for the orbits (represented graphically by the left orbit), vacuities (represented graphically by the left vacuity), and different ratio combinations are illustrated in Figures 4-8, using the first two multivariate axes in each case.

2.1.1. Orbits. In general, large negative values on the first eigenaxis are associated with circular orbit outlines, while large positive values correspond to narrow and elongate orbits (Fig. 4; Supplementary Fig. 1). On the second eigenaxis, large negative values relate to orbits with a subsagittal longitudinal axis, whereas large positive values point to orbits with an anteromedially orientated axis. Phylogenetic signal is strong and significant on the first eigenaxis only. Pagel's lambda shows that tree shape is a good predictor of covariance among species, while Blomberg's K indicates strong partition of trait variance within those groups (i.e., such groups resemble each other less than expected from a null model of trait evolution under BM) (Supplementary Table 2). There is considerable overlap among the taxonomic groups in the central portion of the bivariate scatterplot. Generally, orbit shape provides little support for group separation. In ANOSIM and PERMANOVA, only 16 and 19 (out of 45) pair-wise group comparisons, respectively, are significant without Bonferroni correction, and none when correction is applied (Supplementary Table 1).

2.1.2. Vacuities. From large negative to large positive values on the first eigenaxis, vacuities vary from narrow and spindle-shaped to increasingly wide and isodimensional, and 
occasionally even slightly broader than long (Fig. 5; Supplementary Fig. 2). Shape variation along the second eigenaxis is slightly more complex. Taxa characterized by high negative scores have irregular vacuities, which are often wider anteriorly than posteriorly. The vacuities of taxa with intermediate scores on the second eigenaxis taper at their anterior and posterior extremities in various degrees, with greatest widths located approximately at mid lengths. Taxa that plot on positive scores show posteriorly broad vacuities. Phylogenetic signal is strong and significant for scores on both eigenaxes, and variance is strongly partitioned within groups (Supplementary Table 1). Unlike orbits, vacuities provide better separation among groups in morphospace. In ANOSIM and PERMANOVA, 30 and 31 pairwise group comparisons, respectively, are significant without Bonferroni correction, and 10 and 12 with correction (Supplementary Table 2).

\subsection{Size variation}

The phylPCA analysis of all ratios (Fig. 6; Supplementary Fig. 3) resulted in a slightly higher degree of separation among groups than that supported by shape variables (Supplementary Table 1). As shown in Supplementary Table 2, the variance for each logit-transformed ratio is significantly strongly partitioned between groups, and most ratios show strong phylogenetic signal. The only exception is logit(orbl/sl), for which Pagel's lambda is very low. This indicates that tree structure does not predict the distribution of orbit length as a proportion of skull length. In ANOSIM and PERMANOVA, 29 and 37 pair-wise group comparisons, respectively, are significant without Bonferroni correction, and 12 and 14 with correction (Supplementary Table 2). Very similar patterns are found in the phylPCA of four ratios (Fig. 7; Supplementary Fig. 4), and the only major difference in the pattern of morphosace occupation relative to that of the phylPCA of six ratios is a comparatively wider scatter of taxa along the second Principal Component axis. In total, 28 and 33 pair-wise group 
comparisons are significant, respectively, in ANOSIM and PERMANOVA without Bonferroni correction, and 13 and 15 with correction. When the proportional size of orbits and vacuities relative to one another are used (logit(orbl/vacl); logit(orbw/vacw)), the distribution of taxa in a bivariate scatterplot is almost linear (Fig. 8; Supplementary Fig. 5), with logit(orbl/vacl) and logit(orbw/vacw) exhibiting a moderate and significant positive correlation (Pearson's $\mathrm{r}=0.70164 ; p=0.0001$ corrected for ties). In ANOSIM and PERMANOVA, 25 and 27 pair-wise group comparisons are significant, respectively, without Bonferroni correction, and 10 in both analyses with correction.

\subsection{Evolutionary rates and associated shifts}

The results of motmot revealed contrasting patterns when different cranial variables were used. The analyses of orbit and vacuity shape (in both cases, using the first 10 eigenaxes) supported the occurrence of five rate accelerations (Supplementary Table 3). In the case of orbits, evolutionary rates ranged from more than 7 times in urocordylid nectrideans (branch subtending taxa between Sauropleura pectinata and Ptyonius) to more than 41 times the background rate (branch leading to Platyrhinops). Other notable increases occurred in temnospondyls more derived than dvinosaurs (branch subtending taxa between Acanthostomatops and Platystega; ML rate $>9$ ), the branch leading to Dendrysekos (ML rate $>17$ ), and the trematosauroid branch subtending Lyrocephaliscus and Platystega (ML rate > 20). In the case of vacuities, evolutionary rates ranged from $>4$ times (branch subtending post-dvinosaur temnospondyls) to $>44$ times the background rate (branch subtending Platyrhinops). Other notable increases occurred along the urocordylid branch subtending Urocordylus and Ptyonius (ML rate $>8$ ), the branch leading to Bathignathus (ML rate $>25$ ), and the branch leading to Nyranerpeton (ML rate $>31$ ). 
As for proportional variations in orbits and vacuities, results from rate analysis using all six ratios showed rate heterogeneities (for the results of analyses with four and two ratios, see Supplementary Table 3). The trematosauroid branch subtending taxa between Almasaurus and Koskinonodon experienced a major rate decrease, with a ML rate value about one-fiftieth of the background rate. Another substantial decrease characterized edopoid temnospondyls (branch subtending taxa between Edops and Cochleosaurus bohemicus), where the ML rate was about one-fourth of the background rate. Three increases occurred in micromelerpetid dissorophoids (branch subtending taxa between Nyranerpeton and Branchierpeton; ML rate $>9$ ), in the trematosauroid branch subtending taxa between Bathignathus and Platystega (ML rate $>14$ ), and in amphibamid dissorophoids (branch subtending taxa between Platyrhinops and Amphibamus; ML rate > 54).

\subsection{Shape and size correlation}

A significant, albeit invariably weak, phylogenetically controlled correlation between shape and size was found in just six cases, as follows: orbit ES1 vs. logit(orbl/sl); orbit ES1 vs. logit(vacl/sl); vacuity ES1 vs. logit(orbl/sl); vacuity ES1 vs. logit(orbw/sw); orbit ES2 vs. logit(orbw/sw); vacuity ES1 vs. logit(vacw/sw) (Supplementary Table 4). Visual inspection of the diagnostic plots reveals that, in most tested cases, the PGLS models provide a good fit for the correlated shape-size variables. In particular, the bivariate scatterplots of theoretical vs. sample quantiles show very few (if any), outliers the probability density distributions of residual values are unimodal, and there is no correlation between fitted vs. residual, and observed vs. fitted values.

\section{Discussion}


Despite their relatively simple construction, both orbits and vacuities reveal complex models of shape and size change in temnospondyl evolution (Figs. 4-8). These changes are mostly predicted by phylogenetic structure, and this has interesting implications for the use of orbit and vacuity characters in phylogeny reconstruction.

\subsection{Patterns of orbit shape change}

In the two colosteids (Colosteus; Greererpeton), the orbits show slightly anteromedially orientated longitudinal axes, and those of Greererpeton are proportionally slenderer than those of Colosteus (Fig. 4). Increasingly oblique orbits along the positive direction of the second eigenaxis characterize Proterogyrinus and "microsaurs", in all of which the orbits are slightly narrow. Nectrideans show very different orbit outlines, ranging from subcircular (as in Diplocaulus) to slender and approximately anteroposteriorly elongate in Sauropleura pectinata. In edopoids, the orbits show anteroposteriorly orientated longitudinal axes, and their shapes vary from circular (Cochleosaurus florensis; Edops) to slender (Cochleosaurus bohemicus; Chenoprosopus). The "dendrerpetids" plot out in close proximity to each other, and their orbits with sagittally orientated longitudinal axes are slightly (Balanerpeton) or markedly longer than wide (Dendrerpeton; Dendrysekos). Eryopids and zatracheids exhibit circular (Zatrachys) to slightly ovate (Glaukerpeton) orbits. The dvinosaurs form a compact cluster approximately in the centre of the plot. All of them show slightly ovate orbits and in Dvinosaurus the longitudinal axis is slightly anteromedially orientated. The dissorophoids occupy a large area of morphospace. The orbit shapes in these taxa vary, e.g. almost circular (Dissorophus; lower left corner of the occupied area), broad and anteromedially orientated (Tersomius; upper left corner), moderately slender with sagittally orientated axis (Amphibamus, lower right corner), and distinctly oblique (Broiliellus; upper right corner). Basal stereospondylomorphs plot out almost entirely within the region of morphospace 
occupied by dissorophoids, with orbit shapes varying from circular in Sclerocephalus to moderately slender and anteromedially orientated in Archegosaurus. Similar to dvinosaurs, the capitosauroids plot out in the centre of the diagram (albeit in a larger area than that of dvinosaurs), and their orbits vary from slightly ovate and anteroposteriorly orientated (e.g., Mastodonsaurus; Stanocephalosaurus) to slender and oblique (Parotosuchus denwai). The area occupied by trematosauroids is larger than, and overlaps that of capitosauroids, although trematosauroids are characterized by a wider range of positive scores on both eigenaxes. The brachyopid Bathignathus and the plagiosaurids Gerrothorax and Plagiosternum plot out close to one another. Conversely, Plagiosuchus is a clear outlier. However, we point out that its highly unusual and elongate orbit outline result from the merging of the orbits into a temporal fenestra situated posterior to it (orbitotemporal fenestra of Damiani et al. 2009).

\subsection{Patterns of vacuity shape change}

The two colosteids, as well as Proterogyrinus and "microsaurs", plot out in the left upper corner of the morphospace plot (Fig. 5), where vacuities tend to be slender (in some cases spindle-shaped) with a narrow anterior end and a wider posterior end. As for nectrideans, the two Sauropleura species and Ptyonius also occupy the left upper corner of the graph, but Urocordylus is clearly separated from the other taxa, and its vacuities are widest in their middle part. Diplocaulus and Diploceraspis have broad and ovate vacuities that are widest at approximately their middle part. In edopoids, the vacuities are widest either in their middle part (Cochleosaurus bohemicus; Nigerpeton) or posteriorly (remaining taxa). Furthermore, they range in shape from from slender (Edops) to nearly as wide as long (Cochleosaurus florensis). The "dendrerpetids" plot out close to one another, and their broad vacuities are widest in their posterior part. The eryopids display moderately widened vacuities reaching their maximum width in their middle part. The zatracheids have very broad vacuities which 
reach their greatest width either at mid-length (Zatrachys) or posteriorly (Acanthostomatops).

The dvinosaurs exhibit moderately widened vacuities, with greatest width posteriorly (Trimerorhachis) or anteriorly (Thabanchuia). In most dissorophoids, the much enlarged vacuities are widest slightly posteriorly. In some taxa, such as Amphibamus, Doleserpeton, Dissorophus, and Platyrhinops, the vacuities reach their maximum width in their middle part. Among the basal stereospondylomorphs in our sample, Platyoposaurus has the narrowest vacuities and Capetus has the broadest. Rhineceps, with vacuities that attain their greatest width slightly anterior to their mid length,polot out in the middle of this group's range. The capitosauroids occupy a very restricted area of morphospace, which is situated well within the area occupied by trematosauroids. In capitosauroids, the generally greatly elongate vacuities are widest anteriorly. The pattern of trematosauroids is very similar, except that in some members of this group, the vacuities are widest in their middle part (e.g., Platystega; Lyrocephaliscus). The brachyopid Bathignathus has distinct vacuities that are widest anteriorly and much longer than wide. In the three plagiosaurids, the vacuities are widest in their middle part. Also, whereas the vacuities are longer than wide in Plagiosuchus, in other plagiosaurids they are as wide as (Gerrothorax), or wider than long (Plagiosternum).

\subsection{Patterns of relative size change}

Most outgroups occur in the lower left quadrant of the morphospace plot built from all six cranial ratios (Fig. 6) and are characterized by little or no overlap between the projected orbit and vacuity outlines in a plan view. In contrast, the upper half of the morphospace plot is occupied mostly by temnospondyls. These appear to show a very narrow distribution along the second Principal Component axis (especially along positive scores) and are considerably spread along the first axis. From negative to positive values on the first axis, we observe three main trends for the temnospondyl orbits. Firstly, the orbits tend to increase in relative size. 
Secondly, they tend to shift from a posterior to an anterior or subcentral position on the skull. Thirdly, they tend to become less circular and their longitudinal axis are orientated obliquely in different degrees. As for the vacuities, from left to right these become comparatively broader and rounder and also show complex patterns of eccentricity.

When the two variables summarizing proportional size of orbits and vacuities relative to one another are used (Fig. 8), the outgroups are significantly separated from several temnospondyl groups. Except in the case of dissorophoids and the eryopid-zatracheid group, both of which form compact clusters, most temnospondyl groups occupy a wide range of values on the horizontal axis and small to large ranges of values on the vertical axis (e.g., in capitosauroids and trematosauroids, the distribution of values along the two axes are comparable). This points to a greater amount of diversity in proportional orbit-vacuity lengths than in proportional orbit-vacuity widths, the latter varying conspicuously only in the outgroups.

\subsection{Biological interpretations}

The interpterygoid vacuities of temnospondyls (and certain other early tetrapods with moderately to large-sized interpterygoid vacuities like colosteids) are hypothesized to having accommodated an anteriorly extended portion of the jaw adductors to increase bite force in these mainly long-snouted or long-skulled animals; only the posterior part of the vacuity was filled by frog- or salamander-like extrinsic eye muscles to retract the eye-balls in temnospondyls (Witzmann \& Werneburg 2017). Whereas colosteids and most temnospondyls have orbits that are distinctive smaller than the vacuities, they are considerably proportionally enlarged in such groups as dissorophoids and, to some degree, "dendrerpetids" and plagiosaurids whose interpterygoid vacuities likewise underwent conspicuous increase in proportional size (Figs 5-6). Particularly in dissorophoids and 
"dendrerpetids", the anterior portion of the jaw adductor musculature was probably reduced (because it was biomechanically simply no more "necessary" in a short skull) and that the almost equally enlarged vacuities and orbits served for accommodation of the extrinsic eye muscles and the eye-balls, which were of large size at least in dissorophoids (Witzmann \& Werneburg 2017). We hypothesize that the main or exclusive role of the vacuities in early tetrapods was originally to provide insertion for anterior jaw muscles in a rather elongate, crocodile-like skull, and only in temnospondyls they were occupied additionally by the eye muscles (and, finally, as in dissorophoids and lissamphibians, exclusively by the eyemuscles). In colosteids and basal temnospondyls like Edops (Fig. 7), the small orbits are located quite far away from the tear drop-shaped vacuities, so inwards drawing of the eyeballs into the buccal cavity was hardly possible. In most more derived temnospondyls, the orbits are situated vertically above the vacuities and most often above their posterior portion. However, proportional enlargement of the vacuities in further temnospondyl evolution occurred independently from modifications in orbit proportions, and - as mentioned above only in short-snouted and broad-skulled taxa (such as are exemplified by amphibamid dissorophoids) does orbit re-modelling track that of the vacuities. The results from the PGLS analyses lend some support to this scenario. Thus, in none of the six significant PGLS models is orbit shape correlated with vacuity expansion, but in one model vacuity broadening tends to correlate with orbit widening (relative to overall skull width).

In conclusion, we hope that the present work will initiate further comparative studies of cranial evolution in temnospondyls and other groups of early tetrapods. In particular, the long-standing issue of lissamphibian origins may benefit from current renewed interest in patterns and processes of phenotypic transformation during adaptive radiations, offering impetus for elucidating tempo and mode of structural, functional, and ecological innovations accompanying the emergence of a focal clade. 


\section{Acknowledgements}

The authors would like to dedicate this work to Jenny Clack in honour of her outstanding and inspiring contributions to vertebrate palaeontology. F.W. thanks the Alexander von Humboldt-Foundation (http://www.humboldt-foundation.de) for financial support.

\section{References}

Anderson, M. J. 2001. A new method for non-parametric multivariate analysis of variance. Austral Ecology 26, 32-46.

Bell. M. A. \& Lloyd, G. T. 2015. strap: an R package for plotting phylogenies against stratigraphy and assessing their stratigraphic congruence. Palaeontology 58, 379-89.

Beaumont, E. H. 1977. Cranial morphology of the Loxommatidae (Amphibia: Labyrinthodontia). Philosophical Transactions of the Royal Society London B: Biological Sciences 280, 29-101.

Blomberg, S. P., Garland, T. Jr \& Ives, A. R. 2003. Testing for phylogenetic signal in comparative data: behavioral traits are more labile. Evolution 57, 717-45.

Bossy, K. A. \& Milner, A. C. 1998. Order Nectridea. In Wellnhofer, P. (ed.) Encyclopedia of Paleoherpetology, vol. 1: Lepospondyli, 73-131. München: Verlag Dr. Friedrich Pfeil.

Boy, J. A. 1989. Über einige Vertreter der Eryopoidea (Amphibia: Temnospondyli) aus dem europäischen Rotliegend (?höchstes Karbon-Perm) 2. Acanthostomatops. Paläontologische Zeitschrift 63, 133-51.

Boy, J. A. 1990. Über einige Vertreter der Eryopoidea (Amphibia: Temnospondyli) aus dem europaischen Rotliegend (?höchstes Karbon-Perm) 3. Onchiodon. Paläontologische Zeitschrift 64, 287-312.

Boy, J. A. 1995. Über die Micromelerpetontidae (Amphibia: Temnospondyli) 1. Morphologie und Paläoökologie des Micromelerpeton credneri (Unter-Perm; SW-Deutschland). Paläontologische Zeitschrift 69, 429-57. 
Brusatte, S. L., Benton, M. J., Ruta, M. \& Lloyd, G. T. 2008. Superiority, competition, and opportunism in the evolutionary radiation of dinosaurs. Science 321, 1485-8.

Burnham, K. P. \& Anderson, D. R. 1998. Model Selection and Inference: a Practical InformationTheoretic Approach. New York: Springer. 488 pp.

Butler, R. J. \& Goswami, A. 2008. Body size evolution in Mesozoic birds: little evidence for Cope's rule. Journal of Evolutionary Biology 21, 1673-82.

Carroll, R. L. 1964. The early evolution of the dissorophid amhibians. Bulletin of the Museum of Comparative Zoology 131, 161-250.

Carroll, R. L. \& Gaskill, P. 1978. The Order Microsauria. Memoirs of the American Philosophical Society 126, 1-211.

Carroll, R. L. 1998. Order Microsauria. In Wellnhofer, P. (ed.) Encyclopedia of Paleoherpetology, vol. 1: Lepospondyli, 1-72. München: Verlag Dr. Friedrich Pfeil.

Chase, J. N. 1965. Neldasaurus wrightae, a new rhachitomous labyrinthodont from the Texas Lower Permian. Bulletin of the Museum of Comparative Zoology, Harvard University 133, 155-230.

Clack, J. A. 1992. The stapes of Acanthostega gunnari and the role of the stapes in early tetrapods. In Webster, D. B., Fay, R. R. \& Popper, A. N. (eds) Evolutionary Biology of Hearing, 405-420. New York: Springer-Verlag. 859 pp.

Clack, J. A. 2012. Gaining Ground: The Origin and Evolution of Tetrapods. Bloomington, Indiana: Indiana University Press. 544 pp.

Clack, J. A. \& Milner, A. R. 2010. Morphology and systematics of the Pennsylvanian amphibian Platyrhinops lyelli (Amphibia: Temnospondyli). Transactions of the Royal Society of Edinburgh: Earth Sciences 100, 275-95.

Clarke, K. R. 1993. Non-parametric multivariate analyses of changes in community structure. Australian Journal of Ecology 18, 117-43.

Damiani, R., Schoch, R. R., Hellrung, H., Werneburg, R. \& Gastou, S. 2009. The plagiosaurid temnospondyl Plagiosuchus pustuliferus (Amphibia: Temnospondyli) from the Middle Triassic of Germany: anatomy and functional morphology of the skull. Zoological Journal of the Linnean Society 155, 348-73. 
Deban, S. M. \& Wake, D. B. 2000. Aquatic feeding in salamanders. In K. Schwenk, K. (ed.) Feeding: Form, Function and Evolution in Tetrapod Vertebrates, 65-94. San Diego: Academic Press. $537 \mathrm{pp}$.

Dilkes, D. W. 1990. A new trematopsid amphibian (Temnospondyli: Dissorophoidea) from the Lower Permian of Texas. Journal of Vertebrate Paleontology 10, 222-43.

Duellman, W. E. \& Tueb, L. 1994. Biology of Amphibians. Baltimore: John Hopkins University Press. $696 \mathrm{pp}$.

Fox, J. \& Weisberg, F. 2011. An R Companion to Applied Regression. Thousand Oaks: SAGE Publications. 472 pp.

Francis, E. T. B. 1934. The Anatomy of the Salamander. Oxford: Clarendon Press. 451 pp.

Fröbisch, N. B. \& Schoch, R. R. 2009. Testing the impact of miniaturization on phylogeny: Paleozoic dissorophoid amphibians. Systematic Biology 58, 312-27.

Garamszegi, L. Z. (ed.) 2014. Modern Phylogenetic Comparative Methods and their Application in Evolutionary Biology. New York: Springer. 570 pp.

Godfrey, S. J. \& Holmes, R. B. 1995. The Pennsylvanian temnospondyl Cochleosaurus florensis Rieppel, from the lycopsid stump fauna at Florence, Nova Scotia. Breviora 500, 1-25.

Gubin, Y. M. 1991. [Permian archegosauroid amphibians of the USSR]. Trudy Paleontologichesko Instituta Nauka SSSR 249, 1-138. [In Russian.]

Harmon, L. J., Weir, J. T., Brock, C. D., Glor, R. E. \& Challenger, W. 2008. GEIGER: investigating evolutionary radiations. Bioinformatics 24, 129-31.

Holmes, R. B. 1984. The Carboniferous amphibian Proterogyrinus scheelei Romer, and the early evolution of tetrapods. Philosophical Transactions of the Royal Society of London B: Biological Sciences 306, 431-524.

Holmes, R. B., Carroll, R. L. \& Reisz, R. R. 1998. The first articulated skeleton of Dendrerpeton acadianum (Temnospondyli, Dendrerpetontidae) from the Lower Pennsylvanian locality of Joggins, Nova Scotia, and a review of its relationships. Journal of Vertebrate Paleontology 18, 64-79. 
Hook, R. W. 1983. Colosteus scutellatus (Newberry): a primitive temnospondyl amphibian from the Middle Pennsylvanian of Linton, Ohio. American Museum novitates 2770, 1-41.

Janis, C. M. \& Keller, J. C. 2001. Modes of ventilation in early tetrapods: costal aspiration as a key feature of amniotes. Acta Palaeontologica Polonica 46, 137-70.

Keck, F., Rimet, F., Bouchez, A. \& Franc, A. 2016. phylosignal: an R package to measure, test, and explore the phylogenetic signal. Methods in Ecology and Evolution 6, 2774-80.

Kimmel, C., Sidlauskas, B. \& Clack, J. A. 2009 Linked morphological changes during palate evolution in early tetrapods. Journal of Anatomy 215, 91-109.

Langston, W. Jr. 1953. Permian amphibians from New Mexico. University of California Publications in Geological Sciences 29, 349-416.

Laurin, M. 2010. How Vertebrates Left the Water. Oakland: University of California Press. 224 pp.

Lautenschlager, S., Witzmann, F. \& Werneburg, I. 2016. Palate anatomy and morphofunctional aspects of interpterygoid vacuities in temnospondyl cranial evolution. The Science of Nature $103,1-10$.

Levine, R. P., Monroy, J. A. \& Brainerd, E. L. 2004. Contribution of eye retraction to swallowing performance in the northern leopard frog, Rana pipiens. Journal of Experimental Biology 207, $1361-8$.

Lohmann, G. P. 1983. Eigenshape analysis of microfossils: a general morphometric method for describing changes in shape. Mathematical Geology 15, 659-72.

MacLeod, N. 1999. Generalizing and extending the Eigenshape method of shape space visualization and analysis. Paleobiology 25, 107-38.

Marcé-Nogué, J., Fortuny, J., de Esteban-Trivigno, S., Sánchez, M., Gil, L. \& Galobart, À. 2015. 3D computational mechanics elucidate the evolutionary implications of orbit position and size diversity of early amphibians. PLOS ONE 10 (e0131320), 1-23.

Marjanović, D. \& Laurin. M. 2013. The origin(s) of extant amphibians: a review with emphasis on the "lepospondyl hypothesis". Geodiversitas 35, 207-72.

Milner, A. C. 1980. A review of the Nectridea (Amphibia). In Panchen, A. L. (ed.) The Terrestrial Environment and the Origin of Land Vertebrates, 377-405. London: Academic Press. 633 pp. 
Milner, A. R. 1990. The radiations of temnospondyl amphibians. In Taylor, P. D. \& Larwood, G. P. (eds) Major Evolutionary Radiations, 321-49. Oxford: Clarendon Press. 437 pp.

Milner, A. R. 1993. The Paleozoic relatives of lissamphibians. Herpetological Monographs 7, 8-27. Milner, A. R. 1996. A revision of the temnospondyl amphibians from the Upper Carboniferous of Joggins, Nova Scotia. Special Papers in Palaeontology 52, 81-103.

Milner, A. R. \& Schoch, R. R. 2013. Trimerorhachis (Amphibia: Temnospondyli) from the Lower Permian of Texas and New Mexico: cranial osteology, taxonomy and biostratigraphy. Neues Jahrbuch für Geologie und Paläontologie, Abhandlungen 270, 91-128.

Milner, A. R. \& Sequeira, S. E. K. 1994. The temnospondyl amphibians from the Viséan of East Kirkton, West Lothian, Scotland. Transactions of the Royal Society of Edinburgh, Earth Sciences 84, 331-61.

Milner, A. R. \& Sequeira, S. E. K. 1998. A cochleosaurid temnospondyl amphibian from the Middle Pennsylvanian of Linton, Ohio, USA. Zoological Journal of the Linnean Society 122, 261-90.

Milner, A. R. \& Sequeira, S. E. K. 2011. The amphibian Erpetosaurus radiatus (Temnospondyli, Dvinosauria) from the Middle Pennsylvanian of Linton, Ohio: morphology and systematic position. Special Papers in Palaeontology 86, 57-73.

Mukherjee, R. N. \& Sengupta, D. P. 1998. New capitosaurid amphibians from the Triassic Denwa Formation of the Satpura Gondwana basin, central India. Alcheringa 22, 317-27.

Mundry, R. 2014. Statistical issues and assumptions of Phylogenetic Generalised Least Squares. In Garamszegi, L. Z. (ed.) Modern Phylogenetic Comparative Methods and their Application in Evolutionary Biology, 131-53. New York: Springer. 570 pp.

Orme, C. D. L., Freckleton, R. P., Thomas, G. H., Petzoldt, T., Fritz, S. A. \& Isaac, N. J. B. 2013. CAPER: comparative analyses of phylogenetics and evolution in R. Methods in Ecology and Evolution 3, 145-51.

Pagel, M. 1999. Inferring the historical patterns of biological evolution. Nature 401, 877-84.

Pardo, J. D., Szostakiwskyj, M., Ahlberg, P. E. \& Anderson, J. S. 2017. Hidden morphological diversity among early tetrapods. Nature 546, 642-5. 
Polley, B. P. \& Reisz, R. R. 2011. A new Lower Permian trematopid (Temnospondyli:

Dissorophoidea) from Richards Spur, Oklahoma. Zoological Journal of the Linnean Society 161, 789-815.

Porro, L. B., Rayfield, E. J. \& Clack, J. A. 2015. Descriptive anatomy and three-dimensional reconstruction of the skull of the early tetrapod Acanthostega gunnari Jarvik, 1952. PloS one, 10(3), p.e0118882.

Revell, L. J. 2009. Size-correction and principal components for interspecific comparative studies. Evolution 63, 3258-68.

Romer, A. S. \& Witter, R. V. 1942. Edops, a primitive rhachitomous amphibian from the Texas red beds. The Journal of Geology 50, 925-60.

Ruta, M. \& Bolt, J. R. 2006. A reassessment of the temnospondyl amphibian Perryella olsoni from the Lower Permian of Oklahoma. Transactions of the Royal Society of Edinburgh: Earth Sciences 97, 113-65.

Ruta, M. \& Coates, M. I. 2007. Dates, nodes, and character conflict: addressing the lissamphibian origin problem. Journal of Systematic Palaeontology 5, 69-122.

Ruta, M., Wagner, P. J. \& Coates, M. I. 2006. Evolutionary patterns in early tetrapods. I. Rapid initial diversification followed by decrease in rates of character change. Proceedings of the Royal Society of London B: Biological Sciences 273, 2107-11.s

Sawin, H. G. 1941. The cranial anatomy of Eryops megacephalus. Bulletin of the Museum of Comparative Zoology, Harvard College 88, 405-64.

Schoch, R. R. 2006. A complete trematosaurid amphibian from the Middle Triassic of Germany. Journal of Vertebrate Paleontology 26, 29-43.

Schoch, R. R. 2008. A new stereospondyl from the German Middle Triassic, and the origin of the Metoposauridae. Zoological Journal of the Linnean Society 152, 79-113.

Schoch, R. R. 2012. Character distribution and phylogeny of the dissorophid temnospondyls. Fossil Record 15, 121-37.

Schoch, R. R. 2013. The evolution of major temnospondyl clades: an inclusive phylogenetic analysis. Journal of Systematic Palaeontology 11, 673-705. 
Schoch, R. R. 2014 Amphibian Evolution: The Life of Early Land Vertebrates. Oxford: Wiley Blackwell. 276 pp.

Schoch, R. R. \& Rubidge, B. S. 2005. The amphibamid Micropholis from the Lystrosaurus assemblage zone of South Africa. Journal of Vertebrate Paleontology 25, 502-22.

Schoch, R. R. \& Milner, A. R. 2008. The intrarelationships and evolutionary history of the temnospondyl family Branchiosauridae. Journal of Systematic Palaeontology 6, 409-31.

Schoch, R. R. \& Milner, A. R. 2000. Stereospondyli. In Wellnhofer P. (ed.) Handbuch der Paläoherpetologie, Part 3: Stereospondyli, 1-220. München: Verlag Dr. Friedrich Pfeil.

Schoch, R. R. \& Milner, A. R. 2014. Handbook of Paleoherpetology, Part 3A2: Temnospondyli I, 1150. München: Verlag Dr. Friedrich Pfeil.

Schoch, R. R. \& Witzmann, F. 2009a. Osteology and relationships of the temnospondyl Sclerocephalus. Zoological Journal of the Linnean Society 157, 135-68.

Schoch, R. R. \& Witzmann, F. 2009b. The temnospondyl Glanochthon from the Lower Permian Meisenheim Formation of Germany. Special Papers in Palaeontology 81, 121-36.

Schoch, R. R. and Witzmann, F. 2012. Cranial morphology of the plagiosaurid Gerrothorax pulcherrimus as an extreme example of evolutionary stasis. Lethaia $\mathbf{4 5}, 371-85$.

Sequeira, S. E. K. 1998. The cranial morphology and taxonomy of the saurerpetontid Isodectes obtusus comb. nov. (Amphibia: Temnospondyli) from the Lower Permian of Texas. Zoological Journal of the Linnean Society 122, 237-59.

Sequeira, S. E. K. 2003. The skull of Cochleosaurus bohemicus Frič, a temnospondyl from the Czech Republic (Upper Carboniferous) and cochleosaurid interrelationships. Earth and Environmental Science Transactions of The Royal Society of Edinburgh 94, 21-43.

Sequeira, S. E. K. \& Milner, A. R. 1993. The temnospondyl amphibian Capetus from the Upper Carboniferous of Nýřany, Czech Republic. Palaeontology 36, 657-80.

Shishkin, M. A. 1961. [Recent data on Tupilakosaurus.] Doklady Akademiya Nauk SSSR 136, 938-41. [In Russian.] 
Shishkin, M. A. 1973. [The morphology of the early Amphibia and some problems of lower tetrapod evolution.] Trudy Paleontologicheskogo Instituta Akademia Nauk SSSR 137, 1-257. [In Russian.]

Sigurdsen, T. \& Bolt, J. R. 2010. The Lower Permian amphibamid Doleserpeton (Temnospondyli: Dissorophoidea), the interrelationships of amphibamids, and the origin of modern amphibians. Journal of Vertebrate Paleontology 30, 1360-77.

Sigurdsen, T. \& Green, D. M. 2011. The origin of modern amphibians: a re-evaluation. Zoological Journal of the Linnean Society 162, 457-69.

Smithson, T. R. 1982. The cranial morphology of Greererpeton burkemorani Romer (Amphibia: Temnospondyli). Zoological Journal of the Linnean Society 76, 29-90.

Sokal, R. R. \& Rohlf, F. J. 1995. Biometry. New York: Freeman. 887 pp.

Steyer, J. S., Damiani, R., Sidor, C. A., O’Keefe, F. R., Larsson, H. C., Maga, A. and Ide, O. 2006. The vertebrate fauna of the Upper Permian of Niger. IV. Nigerpeton ricqlesi (Temnospondyli: Cochleosauridae), and the edopoid colonization of Gondwana. Journal of Vertebrate Paleontology 26, 18-28.

Sulej, T. 2007. Osteology, variability, and evolution of Metoposaurus, a temnospondyl from the Late Triassic of Poland. Palaeontologia Polonica 64, 29-139.

Symonds, M. R. E. \& Blomberg, S. P. 2014. A primer on phylogenetic generalised least squares (PGLS). In Garamszegi, L. Z. (ed.) Modern Phylogenetic Comparative Methods and their Application in Evolutionary Biology, 105-130. New York: Springer. 570 pp.

Thomas, G. H. \& Freckleton, R. P. 2012. MOTMOT: models of trait macroevolution on trees. Methods in Ecology and Evolution 3, 145-51.

Vallin, G. \& Laurin, M. 2004. Cranial morphology and affinities of Microbrachis, and a reappraisal of the phylogeny and lifestyle of the first amphibians. Journal of Vertebrate Paleontology 24, 5672.

Wang, M. \& Lloyd, G. T. 2016. Rates of morphological evolution are heterogeneous inEarly Cretaceous birds. Proceedings B 283 (e20160214), 1-9. 
Warren, A. A. 1999. Karoo tupilakosaurid: a relict from Gondwana. Transactions of the Royal Society of Edinburgh: Earth Sciences 89, 145-60.

Warren, A. A. \& Marsicano, C. A. 2000. A phylogeny of Brachyopoidea (Temnospondyli, Stereospondyli). Journal of Vertebrate Paleontology 20, 462-83.

Werneburg, R. 1991. Die Branchiosaurier aus dem Unterrotliegend des Döhlener Beckens bei Dresden. Veröffentlichungen Naturhistorisches Museum Schleusingen 6, 75-99.

Werneburg, R. 1994. Dissorophoiden (Amphibia, Rhachitomi) aus dem Westfal D (Oberkarbon) von Böhmen - Limnogyrinus elegans (Fritsch 1881). Zeitschrift für geologische Wissenschaften 22, $457-66$.

Werneburg, R. 2012. Dissorophoide Amphibien aus dem Westphalian D (Ober-Karbon) von Nýřany in Böhmen (Tschechische Republik) - der Schlüssel zum Verständnis der frühen ,Branchiosaurier'. Semana 27, 3-50.

Werneburg, R. \& Berman, D. S. 2012. Revision of the aquatic eryopid temnospondyl Glaukerpeton avinoffi Romer, 1952, from the Upper Pennsylvanian of North America. Annals of the Carnegie Museum 81, 33-60.

Witzmann, F. 2006. Cranial morphology and ontogeny of the Permo-Carboniferous temnospondyl Archegosaurus decheni Goldfuss, 1847 from the Saar-Nahe Basin, Germany. Earth and Environmental Science Transactions of The Royal Society of Edinburgh 96, 131-62.

Witzmann, F. \& Werneburg, I. 2017. The palatal interpterygoid vacuities of temnospondyls and the implications for the associated eye- and jaw musculature. The Anatomical Record 300, 1240 69.

Yates, A.M., 1999. The Lapillopsidae: a new family of small temnospondyls from the Early Triassic of Australia. Journal of Vertebrate Paleontology 19, 302-20. 


\section{Figure captions}

Figure 1 Schematic view of the right half of the palate in the temnospondyl Balanerpeton woodi (redrawn after Milner and Sequeira, 1994); (A) constituent bones; (B-C) colour-coded right interpterygoid vacuity and right orbit (the orbit is drawn as a superimposed projection in its corresponding position on the skull roof), with added length and width measurements for both openings and for the skull.

Figure 2 Simplified scheme of early tetrapod relationships based on the analysis of Ruta \& Coates (2007) with diagrammatic ventral views of the skulls of representative taxa and groups showing various degrees of development of the interpterygoid vacuities; note the closed palate of baphetids, the narrow and spindle-shaped vacuities of the embolmerous anthracosaur Proterogyrinus, and the greatly enlarged vacuities of temnospondyls. Palates were redrawn after Beaumont (1977), Carroll \& Gaskill (1978), Holmes (1984), Mukherjee \& Sengupta (1998), Clack \& Milner (2010), and Porro et al. (2015).

Figure 3 Time-calibrated supertree of the early tetrapod taxa included in the present study superimposed on a stratigraphic scale.

Figure 4 Pattern of morphospace occupation for the taxa included in the present study, based upon an Eigenshape Analysis of orbit outlines, and using scores on the first two eigenaxes; orbit outlines of representative taxa are superimposed on the plot (see also Supplementary Figure 1). Colour and symbols in Figures 4-8 are: small black circles: colosteids; larger dark pink circles: nectrideans; larger dark green circles: edopoids; brown squares: "dendrerpetids"; light blue squares: dvinosaurs; dark orange rhombs: dissorophoids; dark yellow rhombs: zatracheids and eryopoids; magenta triangles pointing up: basal stereospondylomorphs; 
blue triangles pointing up: trematosauroids; red triangles pointing down: brachyopoids; bright green triangles pointing down: capitosauroids; black squares with plus symbol:

Proterogyrinus and microsaurs.

Figure 5 Pattern of morphospace occupation for the taxa included in the present study, based upon an Eigenshape Analysis of vacuity outlines, and using scores on the first two eigenaxes; vacuity outlines of representative taxa are superimposed on the plot (see also Supplementary Figure 2).

Figure 6 Pattern of morphospace occupation for the taxa included in the present study, based upon a phylogenetic Principal Component Analysis of six ratios that capture proportional size variations in orbits and vacuities, both relative to cranial dimensions and to one another; the plot uses scores on the first two Principal Component axes; schematic illustrations of skulls, orbits, and vacuities of representative taxa are superimposed on the plot (see also Supplementary Figure 3).

Figure 7 Pattern of morphospace occupation for the taxa included in the present study, based upon a phylogenetic Principal Component Analysis of four ratios that capture proportional size variations in orbits and vacuities relative to cranial dimensions; the plot uses scores on the first two Principal Component axes; schematic illustrations of skulls, orbits, and vacuities of representative taxa are superimposed on the plot (see also Supplementary Figure 4).

Figure 8 Pattern of morphospace occupation for the taxa included in the present study, based upon a phylogenetic Principal Component Analysis of two ratios that capture proportional size variations in orbits and vacuities relative to one another; the plot uses scores on the first 
two Principal Component axes; schematic illustrations of skulls, orbits, and vacuities of representative taxa are superimposed on the plot (see also Supplementary Figure 5).

\section{Table caption}

Table 01 All temnospondyls and other early tetrapods considered in the present study, listed by family and suprafamilial ranks and with literature sources from which images were redrawn and digitized. 


\section{SUPPLEMENTARY MATERIAL}

\section{Time-calibrated supertree}

The phylogeny with temporally scaled branches is reproduced below as an object of class "phylo". This file can be opened and manipulated in various phylogenetic R packages.

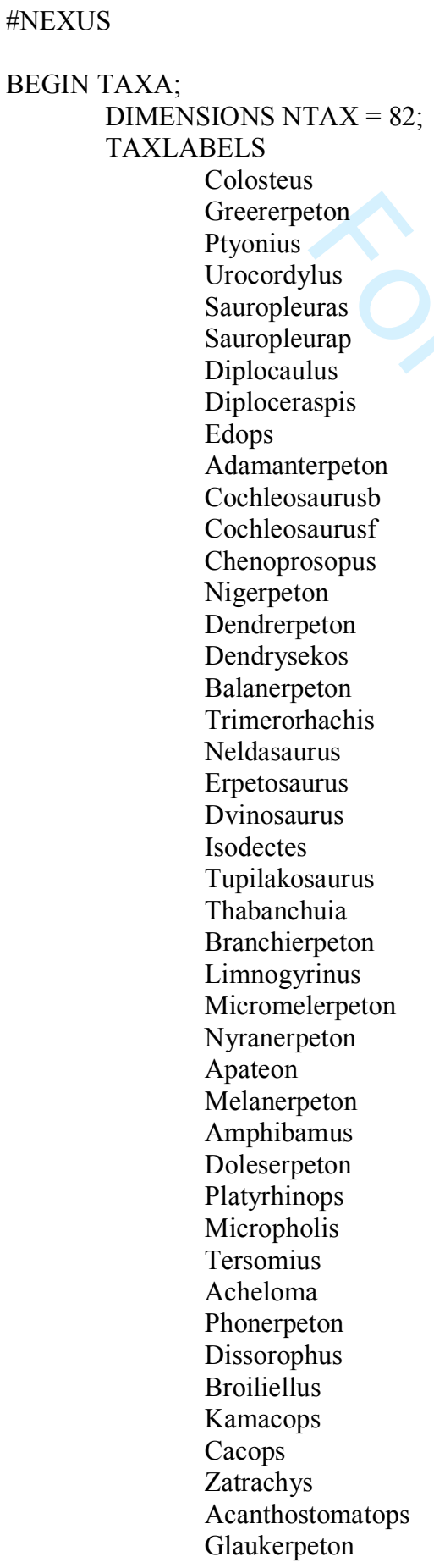


Eryops

Onchiodon

Capetus

Sclerocephalus

Glanochthon

Archegosaurus

Platyoposaurus

Konzhukovia

Rhineceps

Eolydekkerina

Compsocerops

Lapillopsis

Thoosuchus

Trematosaurus

Platystega

Lyrocephaliscus

Trematolestes

Almasaurus

Callistomordax

Koskinonodon

Metoposaurus

Bathignathus

Plagiosuchus

Gerrothorax

Plagiosternum

Benthosuchus

Wetlugasaurus

Parotosuchusd

Stanocephalosaurus

Parotosuchuso

Cyclotosaurus

Eryosuchus

Mastodonsaurus

Proterogyrinus

Microbrachis

Hyloplesion

Micraroter

Rhynchonkos

END;

BEGIN TREES;

TRANSLATE

1 Colosteus,

2 Greererpeton,

3 Ptyonius,

4 Urocordylus,

5 Sauropleuras,

6 Sauropleurap,

7 Diplocaulus,

8 Diploceraspis,

9 Edops,

10 Adamanterpeton,

11 Cochleosaurusb,

12 Cochleosaurusf,

13 Chenoprosopus,

14 Nigerpeton,

15 Dendrerpeton,

16 Dendrysekos,

17 Balanerpeton,

18 Trimerorhachis, 
Neldasaurus,

Erpetosaurus,

Dvinosaurus,

Isodectes,

Tupilakosaurus,

Thabanchuia,

Branchierpeton,

Limnogyrinus,

Micromelerpeton,

Nyranerpeton,

Apateon,

Melanerpeton,

Amphibamus,

Doleserpeton,

Platyrhinops,

Micropholis,

Tersomius,

Acheloma,

Phonerpeton,

Dissorophus,

Broiliellus,

Kamacops,

Cacops,

Zatrachys,

Acanthostomatops,

Glaukerpeton,

Eryops,

Onchiodon,

Capetus,

Sclerocephalus,

Glanochthon,

Archegosaurus,

Platyoposaurus,

Konzhukovia,

Rhineceps,

Eolydekkerina,

Compsocerops,

Lapillopsis,

Thoosuchus,

Trematosaurus,

Platystega,

Lyrocephaliscus,

Trematolestes,

Almasaurus,

Callistomordax,

Koskinonodon,

Metoposaurus,

Bathignathus,

Plagiosuchus,

Gerrothorax,

Plagiosternum,

Benthosuchus,

Wetlugasaurus,

Parotosuchusd,

Stanocephalosaurus,

Parotosuchuso,

Cyclotosaurus,

Eryosuchus,

Mastodonsaurus,

Proterogyrinus, 


$\begin{array}{lll} & 79 & \text { Microbrachis, } \\ & 80 & \text { Hyloplesion, } \\ & 81 & \text { Micraroter, } \\ & 82 & \text { Rhynchonkos } \\ \text { TREE } & & \\ & & *\end{array}$

UNTITLED

$=$

$[\& \mathrm{R}]$

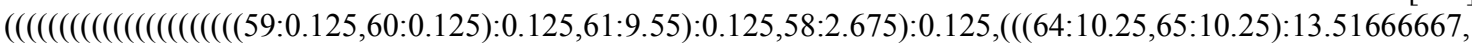
63:3.266666667):3.266666667,62:11.53333333):3.266666667):0.125,(((69:11.65,68:11.65):2.325,67:6.975):2.6 375,66:0.3125):0.3125):0.125,57:0.75):0.125,((((((76:1.366666667,77:11.56666667):1.3666666667,75:12.93333 333):1.541666667,74:0.175):0.175,(72:1.366666667,73:1.366666667):3.083333334):0.175,71:0.525):0.175,70: 0.7):0.175):5.15,((55:32.475,56:1.675):1.675,54:3.35):1.675):5.675,53:4):5.25,52:1.25):14.25,51:13):14,50:1):1, 49:2):5.75,48:4.75):4.898148148,47:0.1481481481):0.1481481481,((45:3.9,46:3.9):5.548148148,44:1.6481481 48):1.648148148):0.1481481481,(((((((38:2.275,39:2.275):2.275,(40:19.775,41:14.175):14.175):2.275,(36:25.3 $125,37: 3.4125): 3.4125): 2.497222222,(((31: 0.05555555556,32: 31.05555556): 0.05555555556,33: 0.1111111111)$ :0.05555555556,(34:41.48333333,35:15.58333333):15.583333333):0.05555555556):0.05555555556,(29:3.53888 8889,30:7.538888889):3.538888889):0.05555555556,((25:10.91111111,26:0.1111111111):0.1111111111,(27:1 2.11111111,28:0.1111111111):0.1111111111):0.1111111111):0.05555555556,(42:3.594444444,43:7.59444444 4):3.594444444):0.05555555556):23.65555556,(((((23:28.45,24:28.45):28.61666667,22:0.1666666667):0.166 6666667,21:49.83333333):6.066666667,20:5.9):5.9,19:21.4):5.9,18:35.7):5.9):16.06666667,((15:9.9,16:9.9):14. 98333333,17:5.083333333):5.083333333):5.083333333,((((11:6.4,12:5.9):5.9,(13:7.75,14:59.05):7.75):5.9,10:1 8.2):5.9,9:31.78):21.15):5.083333333,((((3:11.175,4:1.975):1.975,(5:6.575,6:6.575):6.575):1.975,(7:34.0125,8:1 2.1125):12.1125):24.13055556,(1:28.17777778,2:11.07777778):11.07777778):11.077777778):5.083333333,(((7 9:5.7,80:5.7):5.7,(81:19.95,82:19.95):19.95):24.85833333,78:19.15833333):19.15833333);

END; 

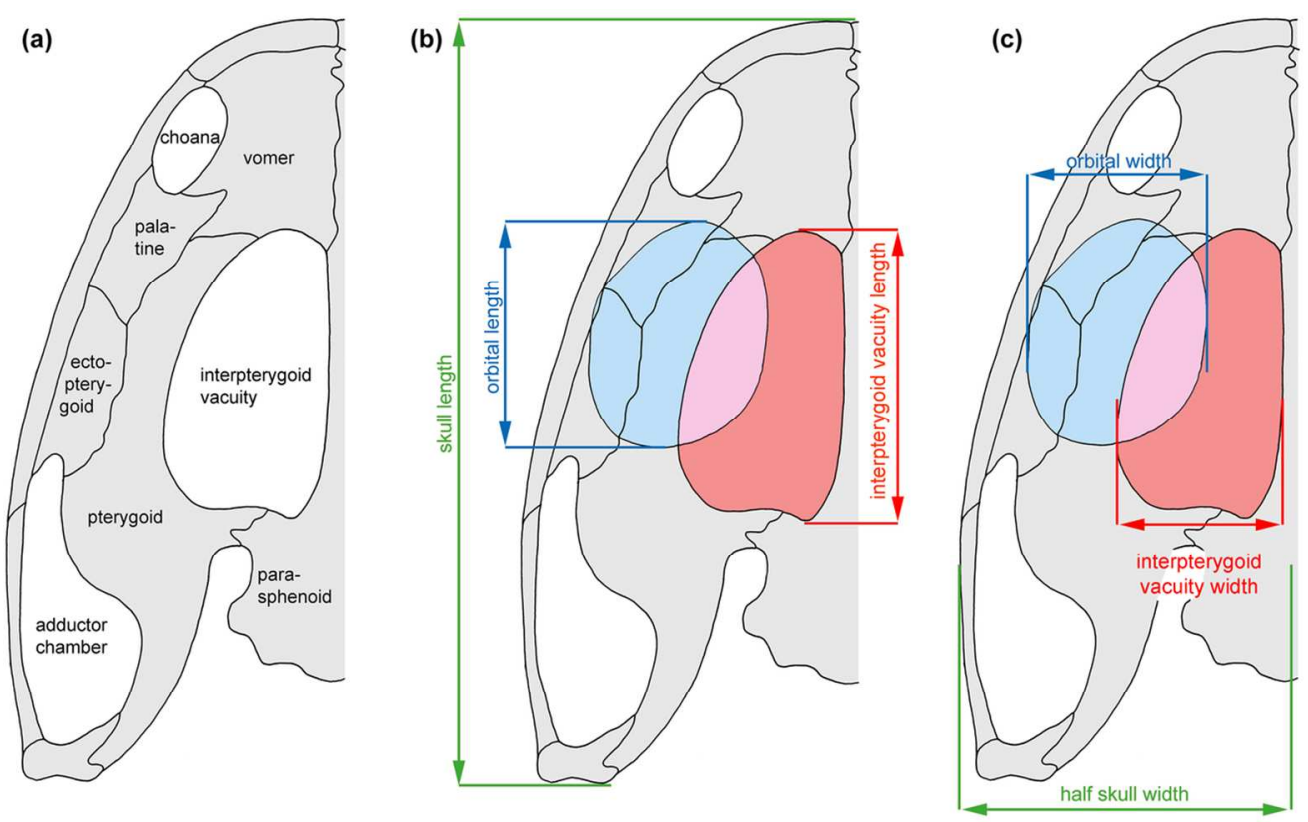

Figure 1 Schematic view of the right half of the palate in the temnospondyl Balanerpeton woodi (redrawn after Milner and Sequeira, 1994); (A) constituent bones; (B-C) colour-coded right interpterygoid vacuity and right orbit (the orbit is drawn as a superimposed projection in its corresponding position on the skull roof), with added length and width measurements for both openings and for the skull.

$111 \times 70 \mathrm{~mm}(300 \times 300$ DPI $)$ 


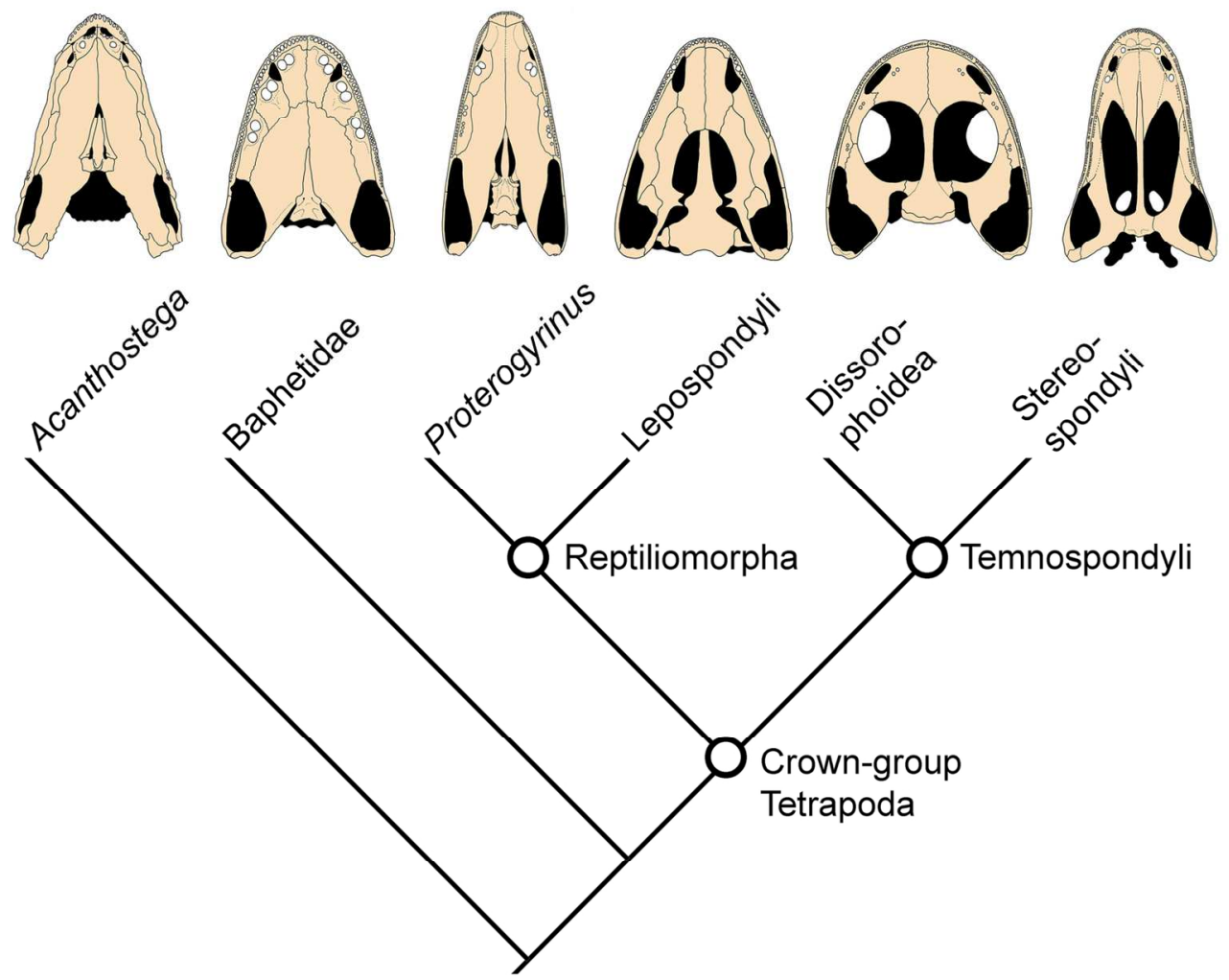

Figure 2 Simplified scheme of early tetrapod relationships based on the analysis of Ruta \& Coates (2007) with diagrammatic ventral views of the skulls of representative taxa and groups showing various degrees of development of the interpterygoid vacuities; note the closed palate of baphetids, the narrow and spindleshaped vacuities of the embolmerous anthracosaur Proterogyrinus, and the greatly enlarged vacuities of temnospondyls. Palates were redrawn after Beaumont (1977), Carroll \& Gaskill (1978), Holmes (1984), Mukherjee \& Sengupta (1998), Clack \& Milner (2010), and Porro et al. (2015).

$$
140 \times 111 \mathrm{~mm}(300 \times 300 \text { DPI) }
$$




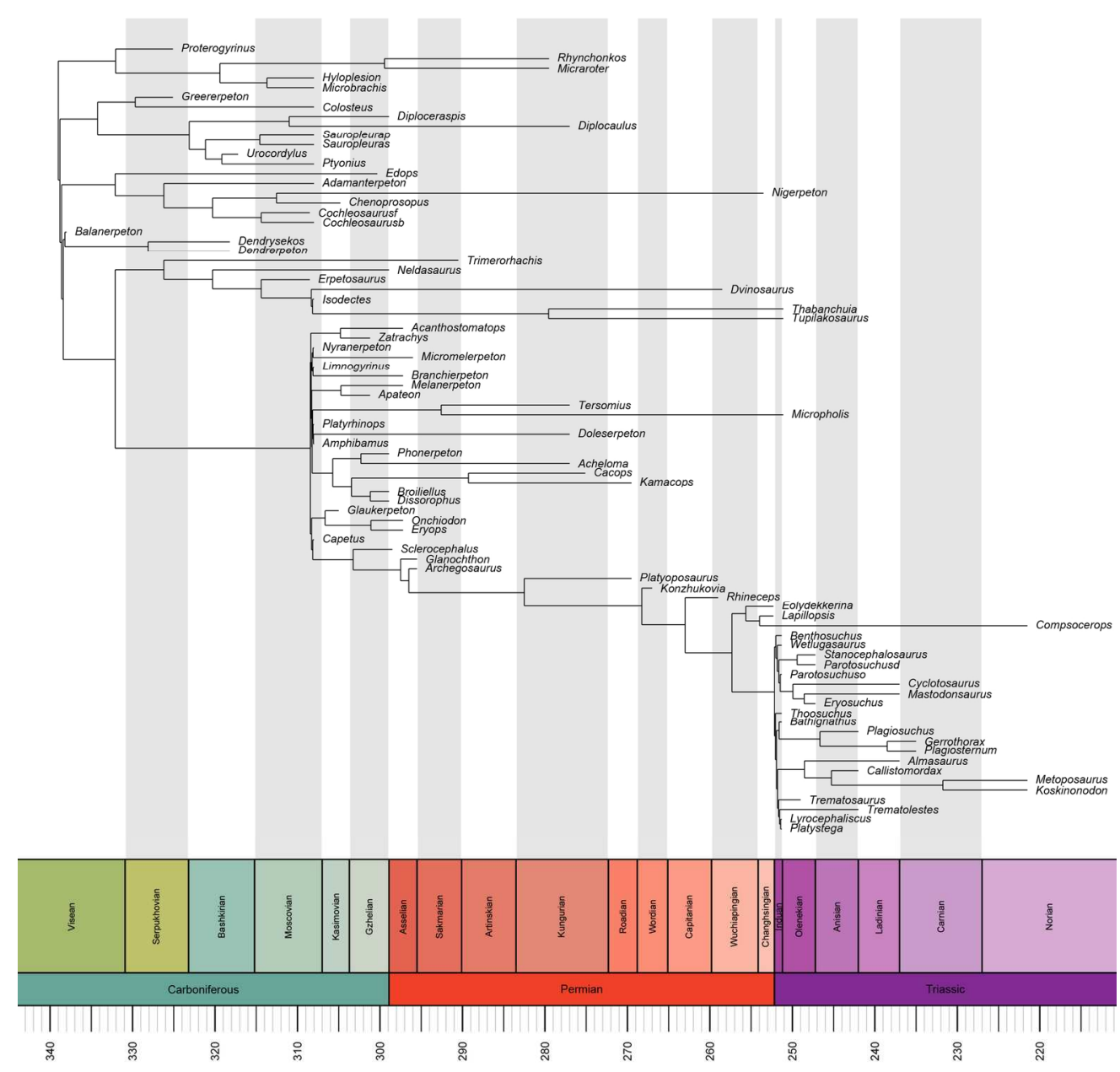

Figure 3 Time-calibrated supertree of the early tetrapod taxa included in the present study superimposed on a stratigraphic scale.

$169 \times 162 \mathrm{~mm}(300 \times 300 \mathrm{DPI})$ 


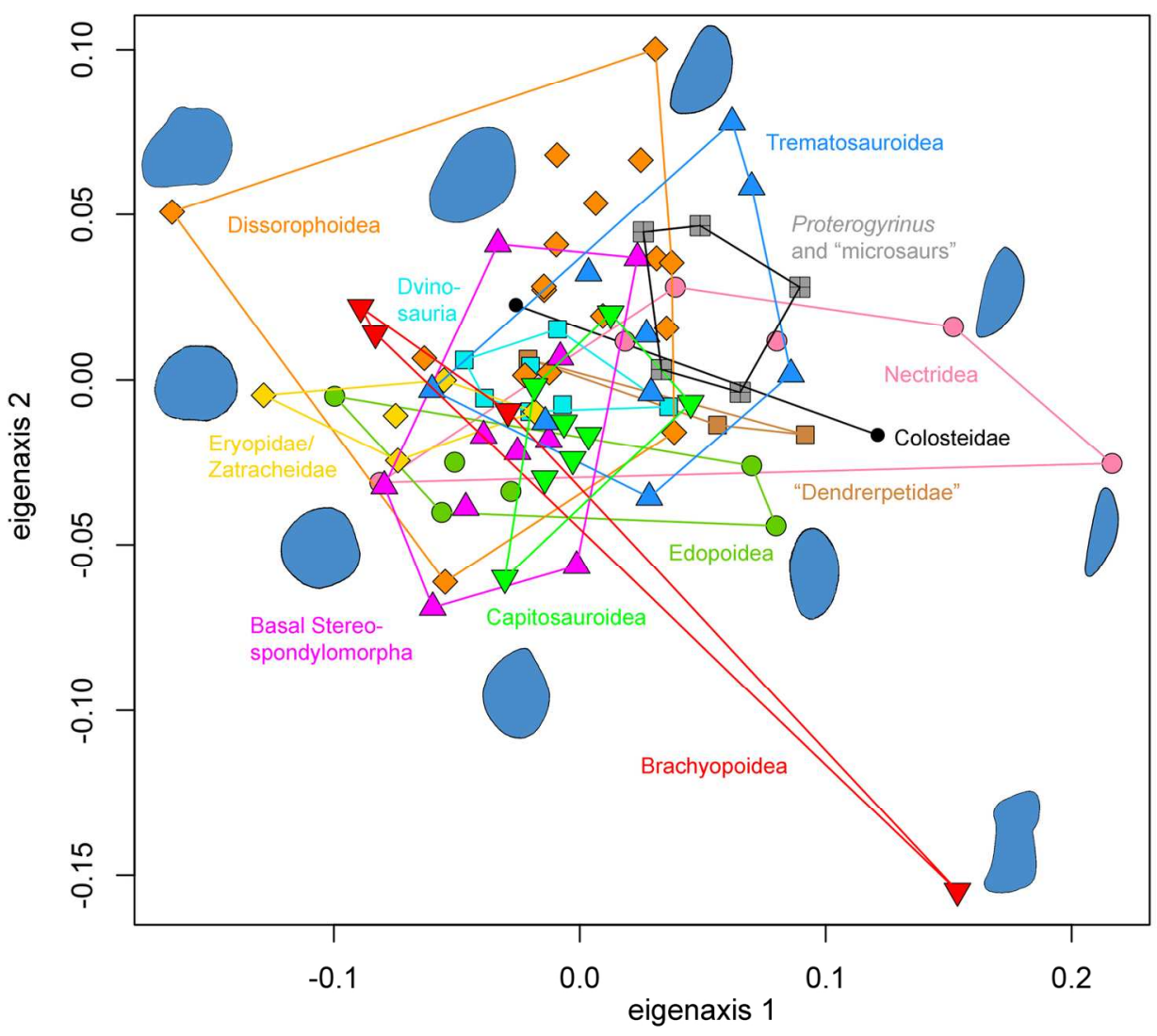

Figure 4 Pattern of morphospace occupation for the taxa included in the present study, based upon an Eigenshape Analysis of orbit outlines, and using scores on the first two eigenaxes; orbit outlines of representative taxa are superimposed on the plot (see also Supplementary Figure 1). Colour and symbols in Figures 4-8 are: small black circles: colosteids; larger dark pink circles: nectrideans; larger dark green circles: edopoids; brown squares: "dendrerpetids"; light blue squares: dvinosaurs; dark orange rhombs: dissorophoids; dark yellow rhombs: zatracheids and eryopoids; magenta triangles pointing up: basal stereospondylomorphs; blue triangles pointing up: trematosauroids; red triangles pointing down: brachyopoids; bright green triangles pointing down: capitosauroids; black squares with plus symbol: Proterogyrinus and microsaurs.

$156 \times 138 \mathrm{~mm}(300 \times 300 \mathrm{DPI})$ 


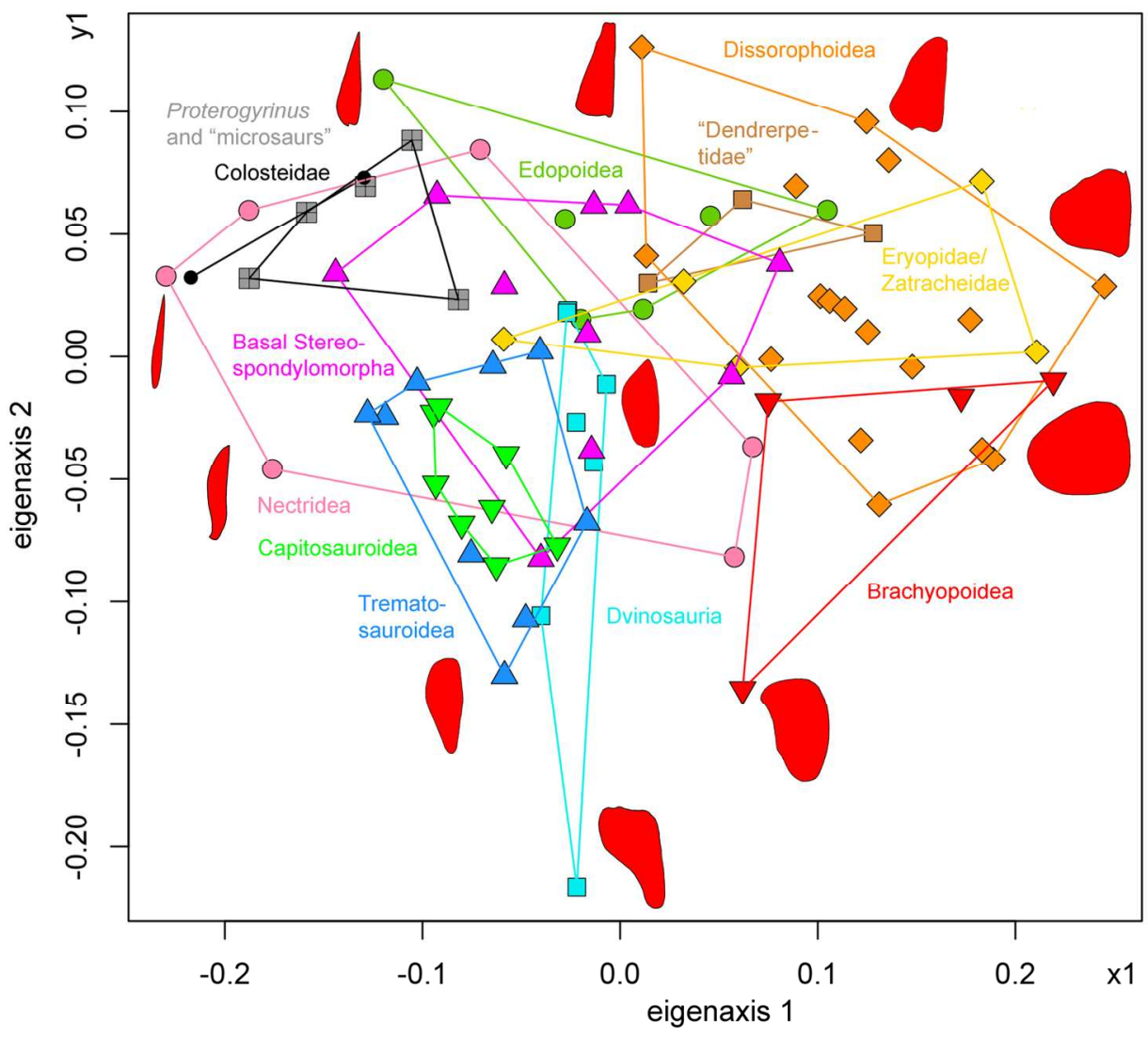

Figure 5 Pattern of morphospace occupation for the taxa included in the present study, based upon an Eigenshape Analysis of vacuity outlines, and using scores on the first two eigenaxes; vacuity outlines of representative taxa are superimposed on the plot (see also Supplementary Figure 2).

$155 \times 135 \mathrm{~mm}(300 \times 300 \mathrm{DPI})$ 


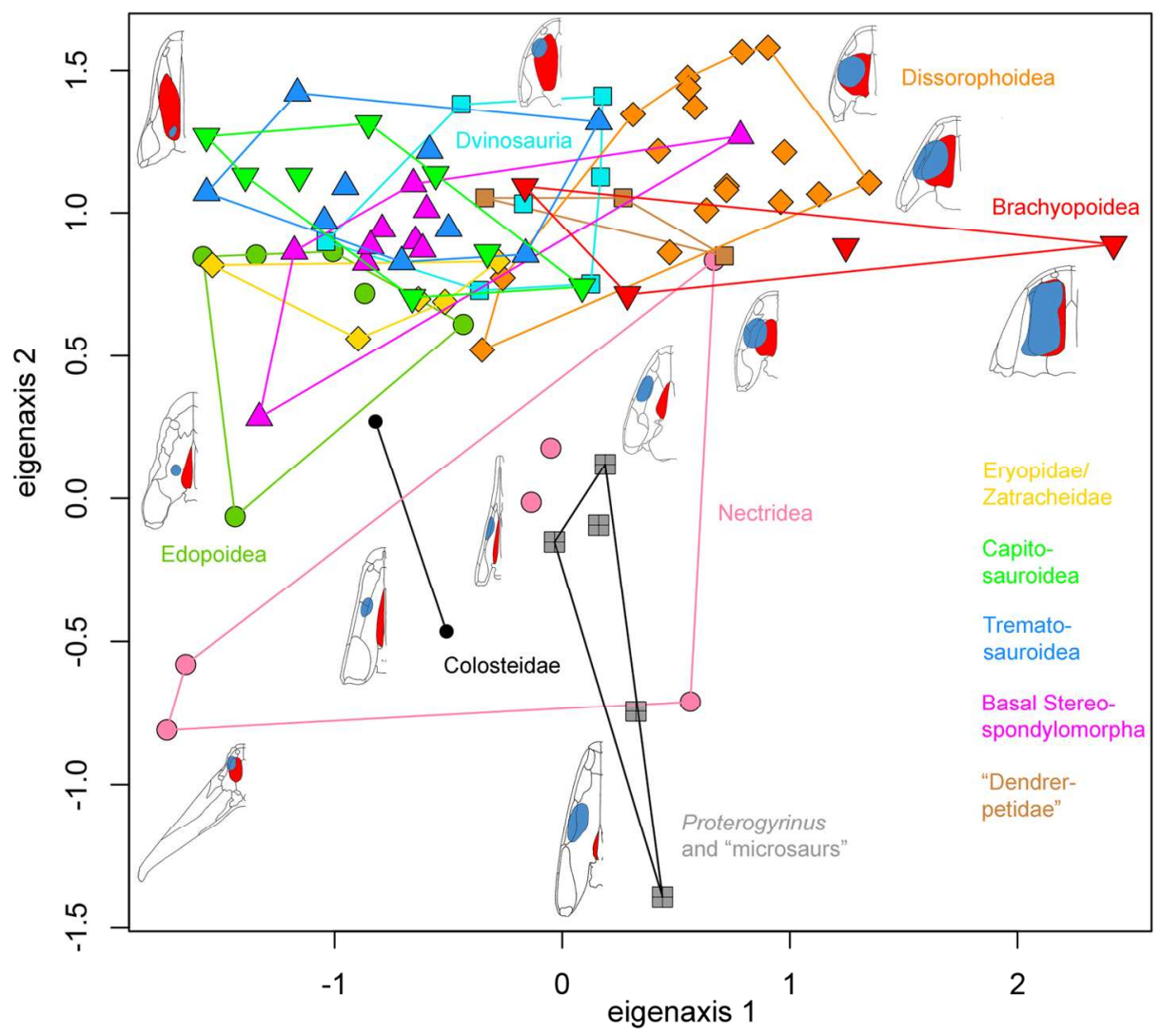

Figure 6 Pattern of morphospace occupation for the taxa included in the present study, based upon a phylogenetic Principal Component Analysis of six ratios that capture proportional size variations in orbits and vacuities, both relative to cranial dimensions and to one another; the plot uses scores on the first two Principal Component axes; schematic illustrations of skulls, orbits, and vacuities of representative taxa are superimposed on the plot (see also Supplementary Figure 3).

$152 \times 132 \mathrm{~mm}(300 \times 300 \mathrm{DPI})$ 


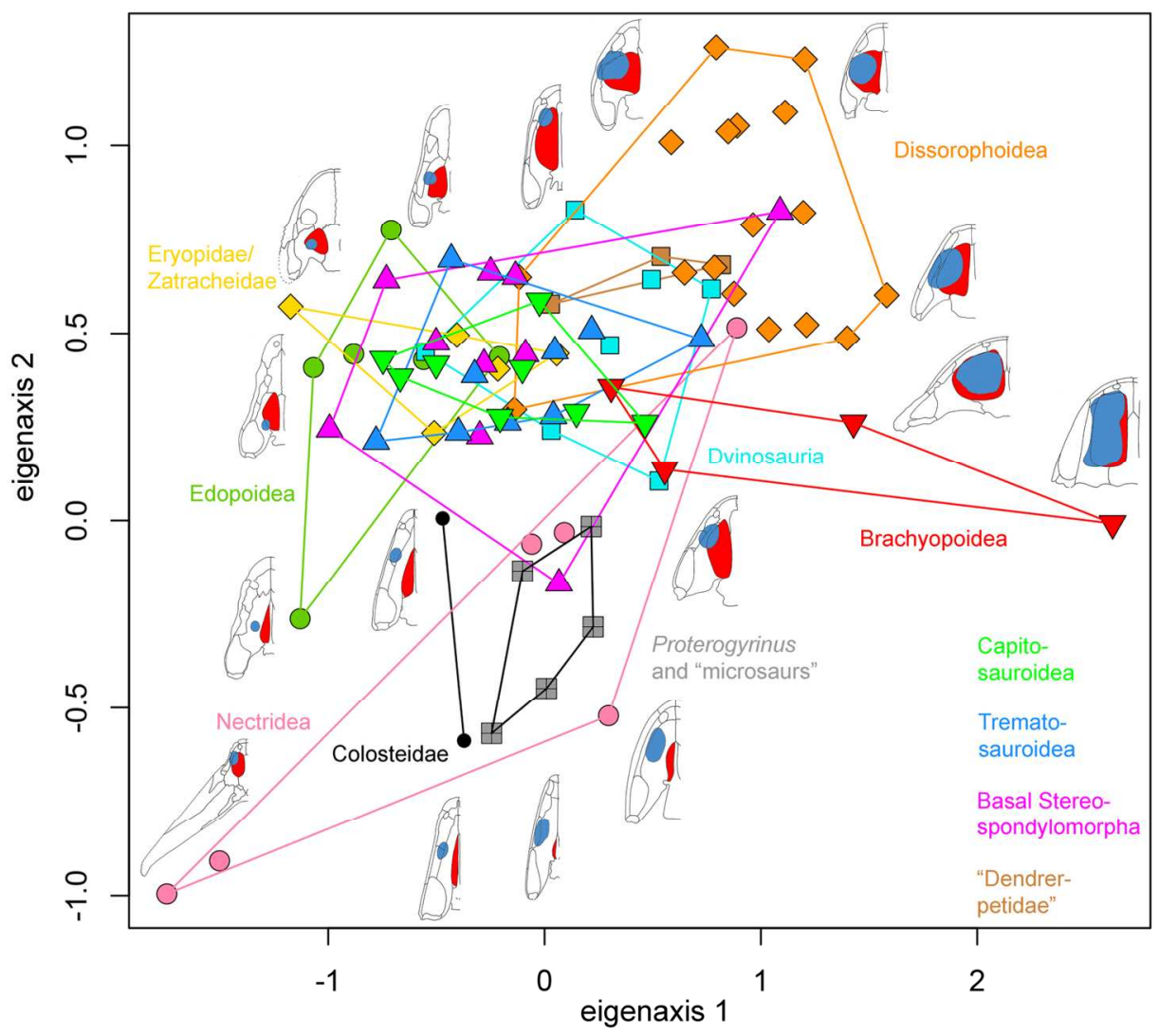

Figure 7 Pattern of morphospace occupation for the taxa included in the present study, based upon a phylogenetic Principal Component Analysis of four ratios that capture proportional size variations in orbits and vacuities relative to cranial dimensions; the plot uses scores on the first two Principal Component axes; schematic illustrations of skulls, orbits, and vacuities of representative taxa are superimposed on the plot (see also Supplementary Figure 4).

$153 \times 133 \mathrm{~mm}(300 \times 300 \mathrm{DPI})$ 


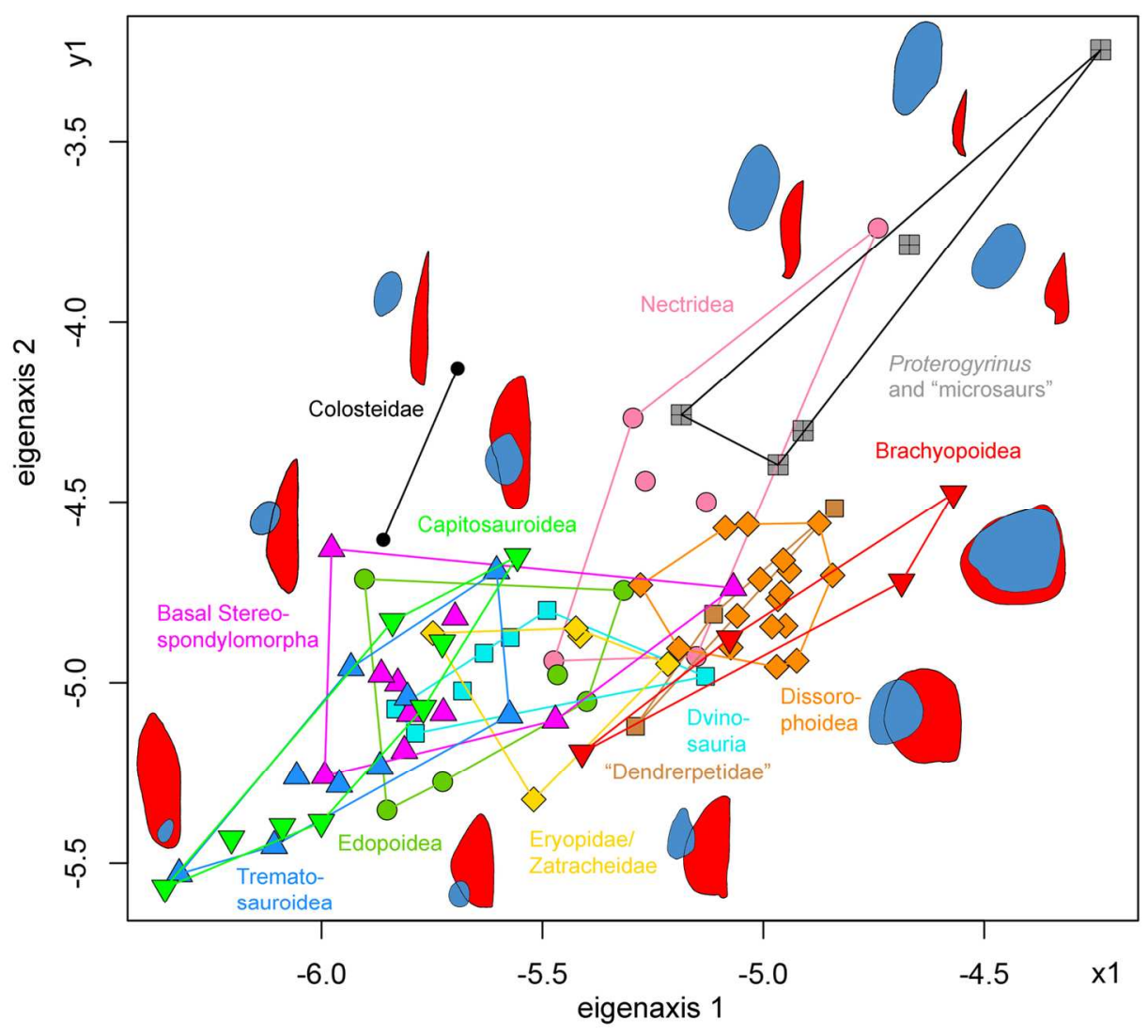

Figure 8 Pattern of morphospace occupation for the taxa included in the present study, based upon a phylogenetic Principal Component Analysis of two ratios that capture proportional size variations in orbits and vacuities relative to one another; the plot uses scores on the first two Principal Component axes; schematic illustrations of skulls, orbits, and vacuities of representative taxa are superimposed on the plot (see also Supplementary Figure 5).

$151 \times 129 \mathrm{~mm}(300 \times 300 \mathrm{DPI})$ 


\section{Suprafamilial rank \\ stem-tetrapods \\ Temnospondyli \\ Edopoidea}

Dvinosauria

Dissorophoidea

\author{
Family \\ Colosteidae \\ Edopidae \\ Cochleosauridae
}

"Dendrerpetidae"

unassigned

Trimerorhachidae

unassigned

Eobrachyopidae

Dvinosauridae

Tupilakosauridae

Micromelerpetidae

Trematopidae

Dissorophidae

Zatracheidae

Eryopidae

Basal Stereospondylomorpha
Sclerocephalidae Intasuchidae

"Archegosauridae"

Melosauridae

Rhinesuchidae

\section{Species}

Greererpeton burkemorani

Colosteus scutellatus

Edops craigi

Adamanterpeton ohioensis

Chenoprosopus milleri

Cochleosaurus bohemicus

Cochleosaurus florensis

Nigerpeton ricqlesi

Dendrerpeton acadianum

Dendrysekos helogenes

Balanerpeton woodi

Capetus palustris

Trimerorhachis insignis

Neldasaurus wrightae

Erpetosaurus radiatus

Isodectes obtusus

Dvinosaurus primus

Tupilakosaurus wetlugensis

Thabanchuia oomie

Branchierpeton amblystomum

Limnogyrinus elegans

Micromelerpeton credneri

Nyranerpeton amilneri

Apateon pedestris

Melanerpeton humbergense

Amphibamus grandiceps

Doleserpeton annectens

Micropholis stowi

Platyrhinops lyelli

Tersomius texensis

Acheloma dunni

Phonerpeton pricei

Dissorophus multicinctus

Kamacops acervalis

Cacops morisi

Broiliellus brevis

Zatrachys serratus

Acanthostomatops vorax

Eryops megacephalus

Glaukerpeton avinoffi

Onchiodon labyrinthicus

Sclerocephalus haeuseri

Glanochthon angusta

Archegosaurus decheni

Platyoposaurus stuckenbergi

Konzhukovia vetusta

Rhineceps nyasaensis 
Trematosauroidea

Capitosauroidea

Brachyopoidea

Anthracosauria Embolomeri Lepospondyli Nectridea

"Microsauria"

Lydekkerinidae
Lapillopsidae
Wetlugasauridae
Benthosuchidae
Thoosuchidae
Trematosauridae
Platystegidae
Lyrocephaliscidae
Almasauridae
Metoposauridae

Parotosuchidae
Mastodonsauridae
Eryosuchidae
Paracyclotosauridae
Cyclotosauridae
Brachyopidae
Chigutisauridae
Plagiosauridae

Eolydekkerina magna Lapillopsis nana

Wetlugasaurus angustifrons

Benthosuchus sushkini

Thoosuchus yakovlevi

Trematolestes hagdorni

Trematosaurus brauni

Platystega depressa

Lyrocephaliscus euri

Almasaurus habbazi

Callistomordax kugleri

Koskinodon perfectus

Metoposaurus diagnosticus

Parotosuchus orenburgensis

Parotosuchus denwai

Mastodonsaurus giganteus

Eryosuchus garjainovi

Stanocephalosaurus pronus

Cyclotosaurus robustus

Bathignathus watsoni

Compsocerops cosgriffi

Plagiosuchus pustuliferus

Gerrothorax pulcherrimus

Plagiosternum granulosum

Proterogyrinidae

Proterogyrinus scheelei

Urocordylidae

Diplocaulidae

Microbrachidae

Hyloplesiontidae

Ostodolepidae

Goniorhynchidae
Ptyonius marshii Urocordylus wandesfordii

Sauropleura scalaris

Sauropleura pectinata

Diplocaulus sp.

Diploceraspis burkei

Microbrachis pelikani

Hyloplesion longicostatum

Micraroter erythrogeios

Rhynchonkos stovalli 


\section{Redrawn and digitized from image}

Smithson 1982, figs 7, 11

Hook 1983, fig. 1a, b

Romer \& Witter 1942, figs 2, 3

Milner \& Sequeira 1998, figs 9, 10

Langston 1953, fig. 8

Sequeira 2004, figs 6, 7

Godfrey \& Holmes 1995, fig. 1

Steyer et al. 2006, fig. 3a, b

Milner 1996, fig. 6

Holmes et al. 1998, fig. 4a, b

Milner \& Sequeira 1994, fig. 5

Sequeira \& Milner 1993, fig 9a, b

Milner \& Schoch 2013, fig. 1

Chase 1965, figs 1, 3

Milner \& Sequeira 2011, fig. 11

Sequeira 1998, fig. 9

Schoch \& Milner 2014, fig. 21

Shishkin 1973, figs 24, 26

Warren 1999, fig. 5a, b

Werneburg 1991, figs 9b, 10c

Werneburg 1994, fig. 1d

Boy 1995, figs 2c, 3c

Werneburg 2012, fig. 21

Schoch \& Milner 2008, figs 3d, 4e

Schoch \& Milner 2008, fig. 4c, f

Schoch \& Milner 2014, fig. 30

Sigurdsen \& Bolt 2010, fig. 4a, b

Schoch \& Rubidge 2005, fig. 2c, d

Clack \& Milner 2010, fig. 9a, b

Carroll 1964, fig. 4

Polley \& Reisz 2011, fig. 1

Dilkes 1990, fig. 1a, b

Schoch 2012, figs 1c, 2c

Schoch 2012, figs 2d, 6

Schoch 2012, figs $3 a, b$

Schoch 2012, figs $1 \mathrm{f}, 2 \mathrm{f}$

Langston 1953, fig. 13

Boy 1989, figs $1 \mathrm{f}, 2 \mathrm{~b}$

Sawin 1941, plates 2, 3

Werneburg \& Berman 2012, figs 3, 11

Boy 1990 , figs $2 \mathrm{f}, 3 \mathrm{~b}$

Schoch \& Witzmann 2009a, fig. 4a, b

Boy 1993, fig. 3; Schoch \& Witzmann 2009b, fig. 3d

Witzmann 2006, fig. 5

Gubin 1991, fig. 3a, b

Schoch \& Milner 2000, fig. 49

Schoch \& Milner 2000, fig. 54 
Schoch \& Milner 2000, fig. 56

Schoch \& Milner 2000, fig. 66

Schoch \& Milner 2000, fig. 73

Schoch \& Milner 2000, fig. 74

Schoch \& Milner 2000, fig. 75

Schoch 2006, fig. 4a, b

Schoch \& Milner 2000, fig. 77

Schoch \& Milner 2000, fig. 82

Schoch \& Milner 2000, fig. 83

Schoch \& Milner 2000, fig. 84

Schoch 2008, fig. 1a, b

Schoch \& Milner 2000, fig. 86

Sulej 2007, figs 1a, $2 a$

Schoch \& Milner 2000, fig. 93

Mukherjee \& Sengupta 1998, fig. 2c, d

Schoch \& Milner 2000, fig. 95

Schoch \& Milner 2000, fig. 97

Schoch \& Milner 2000, fig. 99

Schoch \& Milner 2000, fig. 101

Schoch \& Milner 2014, fig. 47a, b

Warren \& Marsicano 2000, fig. 3b

Damiani et al. 2009, fig. 7a, b

Schoch \& Witzmann 2012, fig. 3a

Damiani et al. 2009, fig. 8c, f

Holmes 1984, fig. 3b, c

Bossy \& Milner 1998, fig. 75a, b

Bossy \& Milner 1998, figs 53f, 55a

Bossy \& Milner 1998, fig. 72a, b

Bossy \& Milner 1998, fig.73a, b

Bossy \& Milner 1998, fig. 56e, 57c

Bossy \& Milner 1998, fig. 80

Vallin \& Laurin 2004, fig. 5a, b

Carroll \& Gaskill 1978, fig. 89b, g

Carroll 1998, figs 1e, 5e

Carroll 1998, fig. 39 